\title{
Metalloproteinase-9 contributes to inflammatory glia activation and nigro-striatal pathway degeneration in both mouse and monkey models of 1-methyl-4-phenyl-1,2,3,6- tetrahydropyrid...
}

ARTICLE in BRAIN STRUCTURE AND FUNCTION · FEBRUARY 2014

Impact Factor: 5.62 · DOI: 10.1007/s00429-014-0718-8· Source: PubMed

CITATIONS

9
READS

169

9 AUTHORS, INCLUDING:

Valentina Annese

Universidad de Sevilla

17 PUBLICATIONS 132 CITATIONS

SEE PROFILE

\section{Loredana Lombardi}

Sapienza University of Rome

8 PUBLICATIONS 31 CITATIONS

SEE PROFILE
Maria Trinidad Herrero

University of Murcia

158 PUBLICATIONS 4,505 CITATIONS

SEE PROFILE

Maria Egle De Stefano

Sapienza University of Rome

52 PUBLICATIONS 803 CITATIONS

SEE PROFILE 


\title{
Metalloproteinase-9 contributes to inflammatory glia activation and nigro-striatal pathway degeneration in both mouse and monkey models of 1-methyl-4-phenyl-1,2,3,6- tetrahydropyridine (MPTP)-induced Parkinsonism
}

\author{
V. Annese - María-Trinidad Herrero • M. Di Pentima • \\ A. Gomez • L. Lombardi • C. M. Ros • V. De Pablos • \\ E. Fernandez-Villalba $\cdot$ Maria Egle De Stefano
}

Received: 8 August 2013/ Accepted: 27 January 2014

(c) Springer-Verlag Berlin Heidelberg 2014

\begin{abstract}
Inflammation is a predominant aspect of neurodegenerative diseases, manifested by glia activation and expression of pro-inflammatory mediators. Studies on animal models of Parkinson's disease (PD) suggest that sustained neuroinflammation exacerbates degeneration of the dopaminergic (DA) nigro-striatal pathway. Therefore, insights into the inflammatory mechanisms of PD may help the development of novel therapeutic strategies against this disease. As extracellular matrix metalloproteinases (MMPs) could be major players in the progression of Parkinsonism, we investigated, in the substantia nigra and striatum of mice acutely injected with 1-methyl-4-phenyl1,2,3,6-tetrahydropyridine (MPTP), changes in mRNA expression, protein levels, and cell localization of MMP-9. This protease is mainly neuronal, but early after MPTP injection its mRNA and protein levels, as well as the
\end{abstract}

V. Annese · M. Di Pentima - L. Lombardi .

M. E. De Stefano $(\square)$

Istituto Pasteur-Fondazione Cenci Bolognetti, Dipartimento di

Biologia e Biotecnologie "Charles Darwin”, Sapienza

Università di Roma, P.le Aldo Moro 5, 00185 Rome, Italy

e-mail: egle.destefano@uniroma1.it

V. Annese · M.-T. Herrero $(\bowtie) \cdot$ A. Gomez .

C. M. Ros · V. De Pablos - E. Fernandez-Villalba

Clinical and Experimental Neuroscience (NiCE-CIBERNED),

School of Medicine, University of Murcia, 30100 Murcia, Spain

e-mail: ezquerro@uji.es

M.-T. Herrero - C. M. Ros

Clinical and Experimental Neuroscience (NiCE-CIBERNED),

School of Health Scences (Medicine), University of Jaume I,

12071 Castelló de la Plana, Spain

M. E. De Stefano

Center for Research in Neurobiology, Sapienza Università di

Roma, 00185 Rome, Italy number of MMP-9-expressing microglia and astrocytes, increase concomitantly to a prominent inflammation. Neuroinflammation and MMP- ${ }^{+}$glia begin to decline within 2 weeks, although protein levels remain higher than control, in association with a partial recovery of DA nigrostriatal circuit. Comparable quantitative studies on MMP-9 knock-out mice, show a significant decrease in both glia activation and loss of DA neurons and fibers, with respect to wild-type. Moreover, in a parallel study on chronically MPTP-injected macaques, we observed that perpetuation of inflammation and high levels of MMP-9 are associated to DA neuron loss. Our data suggest that MMP-9 released by injured neurons favors glia activation; glial cells in turn reinforce their reactive state via autocrine MMP-9 release, contributing to nigro-striatal pathway degeneration. Specific modulation of MMP-9 activity may, therefore, be a strategy to ameliorate harmful inflammatory outcomes in Parkinsonism.

Keywords Metalloproteinases - Neuroinflammation · Parkinson's disease $\cdot$ Neurodegeneration

\section{Introduction}

Parkinson's disease (PD) is a neurodegenerative disorder characterized by progressive loss of dopaminergic (DA) neurons in the substantia nigra pars compacta ( $\mathrm{SNpc}$ ) (Hirsh et al. 1998; Braak et al. 2003, 2006). Idiopathic PD affects mainly the elderly, but it can also develop in young people, where a genetic component may play a prominent role (Houlden and Singleton 2012). The etiology of this disease remains to be elucidated; however, as PD is characterized by a prominent inflammatory reaction, which becomes chronic along the years, neuroinflammation may 
play a role in exacerbation (Hirsch and Hunot 2009; Tansey and Goldberg 2010), or even promotion (Whitton 2010), of the disease. Post-mortem analysis (McGeer et al. 1988; Hirsh et al. 1998; Ouchi et al. 2005, 2009; Braak et al. 2007) and in vivo imaging (Ouchi et al. 2005, 2009; Gerard et al. 2006) of PD patient brains showed activation of microglia, astrogliosis and infiltration of peripheral immune cells in the $\mathrm{SN} p c$ and other regions. These features were also observed in the brain of young drug addicts, who made use of the neurotoxin 1-methyl-4-phenyl-1,2,3,6tetrahydropyridine (MPTP) (Langston et al. 1983), and in animal models of Parkinsonism, such as MPTP-injected mice and monkeys (Barnum and Tansey 2010; Walsh et al. 2011). Increased levels of pro-inflammatory cytokines in both SN (Hunot et al. 1996; Hirsh et al. 1998; Barcia et al. 2005, 2011) and cerebrospinal fluid (Nagatsu et al. 2000; Pott Godoy et al. 2008) of PD patients and animal models have also been described. The complexity of the immune response, however, does not allow to unequivocally establish whether reactive "neuroglia" contributes to DA neuron death. Anti-inflammatory therapies are used in the treatment of a number of neurodegenerative disorders, including PD (Whitton 2010; L'Episcopo et al. 2010); however, from a drug-development perspective, a complete understanding of the factors and mechanisms ruling the onset and progression of disease-specific inflammatory processes is most needed. An intriguing idea is that glial cells may play important and diverse roles during the progression of the disease, a critical moment being the switch from acute to chronic inflammation.

Matrix metalloproteinases (MMPs) are extracellular proteases that finely modulate several physiological and pathological/inflammatory processes (Parks et al. 2004; Page-McCaw et al. 2007; Candelario-Jalil et al. 2009; Wright and Harding 2009). MMP-2 and -9 are highly expressed in the brain in physiological conditions, and MMP-9 and -3 are significantly up-regulated in several brain pathologies, including PD (Lorenzl et al. 2002, Kim et al. 2007, 2011; Choi et al. 2008), highlighting them as possible therapeutic targets (Leonardo and Pennypacker 2009). Specific MMP inhibitors have been developed; however, indiscriminate block of this enzymatic activity is a dangerous ground, since MMPs play different roles depending on the type of pathology and time of activation.

In this study, we investigated changes in MMP-9 expression and localization in the MPTP mouse and monkey models of Parkinsonism. Our results indicate that: (1) MMP-9 is important for inflammatory glia activation, which in turn exacerbates DA neuron loss; (2) at later stages, when neuroinflammation subsides, MMP-9 may contribute to partial recovery of the nigro-striatal pathway.

\section{Materials and methods}

All studies were carried out in accordance with the guidelines promulgated in the National Institutes of Health Guide for the Care and Use of Laboratory Animals (NIH Guide, revised 1996), in the European Convention for the protection of Vertebrate Animals used for Experimental and other scientific purposes of the Council of Europe (no 123, June 15th, 2006), and in accordance with The Code of Ethics of the EU Directive 2010/63/EU. All efforts were made to minimize animal suffering, to reduce the number of animals used, and to utilize alternatives to in vivo techniques. The experimental procedures and protocols were approved by the Ethical Committee for Animal Research of the University of Murcia and of the Italian Ministry of Public Health.

\section{MPTP treatment}

\section{Mice}

We used 3-month-old male C57BL/6J mice, B6.FVB(Cg)$M m p 9^{t m 1 T v u} / \mathrm{J}$ mice and their matching wild-type (WT) mice (The Jackson Laboratory, Bar Harbor, MA, USA). Mice were housed in a separate room, at $21{ }^{\circ} \mathrm{C}$, under a $12 \mathrm{~h}$ (h) day-night cycle and with food and water ad libitum. Acute MPTP treatment was performed according to established protocols (Jackson-Lewis et al. 1995). Briefly, mice received four intra-peritoneal (i.p.) injections of $20 \mathrm{mg} / \mathrm{kg}$ of MPTP HCl (Sigma-Aldrich, St. Louis, MO, USA) dissolved in $0.9 \% \mathrm{NaCl}$ at $2 \mathrm{~h}$ intervals. We always used freshly diluted MPTP and adopted special animal care (i.e. warm room temperature and cages provided with cotton wool) to minimize mice loss after treatment. Only five mice over the total used (see details below) died after MPTP injection. Control mice received equivalent injections of saline. The number of mice used was: for molecular biology and biochemical studies, 8 mice/experimental group and type of analysis, for a total of 112 mice (56 mice each); for confocal microscope analysis, 4 mice/experimental group, for a total of 20 mice; for immunohistochemistry, 5 WT mice/experimental group and 8 MMP-9 KO mice/experimental group, for a total of $15 \mathrm{WT}$ and 24 MMP-9 KO mice, respectively. Mice were killed at established time points (see specific paragraphs) and brains removed and processed for the different types of analyses.

\section{Macaques}

Brain sections were derived from a colony of chronic parkinsonian macaques (Macaca fascicularis) previously established and studied at the Primate Unit of the University of Murcia, and were properly stored. Samples were 
Table 1 Motor score of Parkinsonism evaluated for each monkey, cumulative dose of MPTP received and time of survival after the last MPTP administration

\begin{tabular}{lllll}
\hline Monkey & Sex & Motor score & MPTP $(\mathrm{mg} / \mathrm{Kg})$ & Years after MPTP \\
\hline C1 & M & 0.0 & 0 & - \\
C2 & M & 0.0 & 0 & - \\
C3 & F & 0.0 & 0 & - \\
P1 & M & 3.5 & 1.8 & 2 \\
P2 & F & 4.2 & 0.9 & 2 \\
P3 & M & 5.0 & 1.8 & 2 \\
P4 & F & 9.2 & 0.9 & 2 \\
\hline
\end{tabular}

$C$ control, $P$ Parkinsonian, $M$ male, $F$ female

obtained from six young adult macaques, four of which had been treated weekly with low intravenous doses of MPTP $(0.3 \mathrm{mg} / \mathrm{kg})$ until stable Parkinsonism was established (Herrero et al. 1993; Barcia et al. 2003). This varied, depending on individual susceptibility to the toxin. Progressive motor alterations were assessed using a rating scale ranging from 0 to 25 (Herrero et al. 1993) (Table 1). Parkinsonian macaques were killed 2 years after the last MPTP administration. Monkeys not treated with MPTP were used as controls. For this study, three controls and 5 parkinsonian macaques were used.

Real-Time reverse transcriptase-polymerase chain reaction

mRNA levels of MMP-9 were assessed in the brain of control and MPTP-treated C57BL/6J mice by Real Time Reverse transcriptase-Polymerase Chain Reaction (RTPCR). Animals were deeply anesthetized with isoflurane (Merial, Harlow, UK) and killed by decapitation at different time points after the last MPTP injection: 1, 24, 48, $72 \mathrm{~h}, 1$ week and 2 weeks. Brains were rapidly removed, frozen in liquid nitrogen-cooled isopentane, and stored at $-80{ }^{\circ} \mathrm{C}$ until use. Frozen brains were cut in $1 \mathrm{~mm}$-thick coronal sections on a matrix for brain slicing (AgnTho's, Lidingö, Sweden), and dorsal striatum and SN were removed by excision with a thin needle and a punching device of $0.75 \mathrm{~mm}$ of internal diameter (AgnTho's), respectively. Samples were rapidly homogenized for RNA extraction.

\section{$R N A$ extraction, quantification and reverse transcription}

Total RNA was isolated from SN and striatum of control and MPTP-treated C57BL/6J mice using the RNeasy Micro kit (Qiagen, Milan, Italy) according to the manufacturer's instructions. RNA was purified from genomic DNA using the DNA-free kit (Ambion, Austin, TX, USA), and quantity and purity were assessed by the Nanodrop ND1000 spectrophotometer at $260 \mathrm{~nm}$. RNA integrity was assessed by electrophoresis on ethidium bromide-stained $1 \%$ agarose-formaldehyde gels. RNA was reverse-transcribed as previously described (Del Signore et al. 2006) using the cDNA synthesis kit (Bioline, London, UK). cDNA samples were stored at $-20{ }^{\circ} \mathrm{C}$ until use.

\section{Real-time RT-PCR}

$2.5 \mu \mathrm{l}$ of cDNA was amplified by real-time RT-PCR in $25 \mu \mathrm{l}$ of a reaction mixture containing $12.5 \mu \mathrm{l}$ of $2 \times \mathrm{SYBR}$ Green JumpStart Taq ReadyMix (Sigma-Aldrich), $0.25 \mu \mathrm{l}$ of Internal Reference Dye and $3 \mu \mathrm{l}$ of each specific primer ( $5 \mu \mathrm{M}$ final concentration forward + reverse) (SigmaAldrich), using an iCycler iQ Real-Time Detection System (Bio-Rad, Milan, Italy). Each sample was amplified in duplicate for 30-35 cycles. Amplicons were detected after each elongation step and analyzed using the iCycler iQ software (Bio-Rad). A melting curve was obtained after completion of the cycles to verify the presence of a single amplified product. Relative quantification was carried out with the $2^{-\Delta \Delta \mathrm{Ct}}$ method (Livak and Schmittgen 2001), using the abundance of hypoxanthinephospho-ribosyltransferase (HPRT) as endogenous house-keeping control. The specificity of each pair of primers was confirmed by comparing to a negative control with water. Primers used were the following:

MMP-9 F, 5'-GGCGTGTCTGGAGATTCG-3', R, 5'ATGGCAGAAATAGGCTTTGTC-3';

HPRT F, 5'-AGTCCCAGCGTCGTGATTAG-3', R, 5' CCATCTCCTTCATGACATCTCG- ${ }^{\prime}$

\section{Western immunoblot}

\section{Primary antibodies}

Rabbit polyclonal antibodies against MMP-9 $(1: 2,000)$ and tyrosine hydroxylase $(\mathrm{TH})(1: 1,000)$ were from Chemicon (Temecula, CA, USA). Mouse monoclonal antibody against glyceraldehyde phosphate dehydrogenase (GAPDH, 1:5,000) was from Abcam (Cambridge, UK).

Preparation of tissue extracts, electrophoresis and immunoblotting

Time periods of MPTP treatment and tissue preparation from control and MPTP-treated C57BL/6J mice were as described for real-time RT-PCR. Tissues were homogenized with a ground-glass micro-homogenizer in ice-cold RIPA buffer $(50 \mathrm{mM}$ Tris/ $\mathrm{HCl} \mathrm{pH} 7.6,150 \mathrm{mM} \mathrm{NaCl}$, $1 \mathrm{mM}$ EDTA, $1 \%$ SDS, $1 \%$ Triton $\mathrm{X}-100,1 \times$ of a cocktail of inhibitors, $1 \mathrm{mM}$ PMSF, $0.2 \mathrm{mM} \mathrm{Na}_{3} \mathrm{VO}_{4}$ and 
$1 \mathrm{mM} \mathrm{NaF})$. After centrifugation $(15,000 \times g, 15 \mathrm{~min}$ at $4{ }^{\circ} \mathrm{C}$ ), a measured volume of supernatant was analyzed to determine total protein concentration using the Micro BCA kit (Pierce, Rockford, IL, USA). Other aliquots of the supernatant were diluted with $4 \times$ reducing loading buffer (200 mM Tris/ $\mathrm{HCl}$ pH 6.8, $4 \%$ SDS, $30 \%$ glycerol, $4 \%$ $\beta$-mercaptoethanol, $4 \%$ blue bromophenol), boiled for $3 \mathrm{~min}$ at $100{ }^{\circ} \mathrm{C}$, and stored at $-20{ }^{\circ} \mathrm{C}$ until use.

Eighty micrograms of proteins of each sample were separated on $8 \%$ SDS-polyacrylamide gels. Loading of such a high amount of proteins was necessary to obtain a proper densitometric signal, as the levels of MMP-9 in SN and striatum from a single mouse are too low with respect to total protein content. Molecular mass standard (ColorBurst $^{\odot}$, Sigma-Aldrich), containing precisely sized recombinant proteins of 210, 90, 65, 40, 30, 20, 13 and $8 \mathrm{kDa}$, along with human recombinant gelatinases MMP-9 and MMP-2 (used as positive controls), were loaded on separate lanes next to the specimen homogenates. Gels were run at a constant $200 \mathrm{~V}$, proteins transferred overnight onto a nitrocellulose membrane (transfer buffer: $50 \mathrm{mM}$ Tris/ $\mathrm{HCl}, 380 \mathrm{mM}$ glycine, $0.1 \%$ SDS and $20 \%$ methanol) and correct electrophoretic migration and uniform protein loading were verified by Ponceau $\mathrm{S}$ staining (Biorad). Non-specific binding sites were blocked in $5 \%$ dry milk (DM) (Carnation instant no-fat milk, Nestlé, USA), diluted in $1 \times$ TBST $(20 \mathrm{mM}$ Tris/HCl $\mathrm{pH} 7.5$, $500 \mathrm{mM} \mathrm{NaCl}, 0.05 \%$ Tween-20) ( $2 \mathrm{~h}$ at RT). Membranes were successively incubated (overnight at $4{ }^{\circ} \mathrm{C}$ ) with the primary antibodies (diluted in $3 \% \mathrm{BSA}, 0.05 \% \mathrm{NaN}_{3}, 1 \times$ TBST) and then ( $1 \mathrm{~h}$ at RT) with the appropriate horseradish peroxidase (HRP)-conjugated secondary antibody (Promega, Madison, WI, USA): goat anti-rabbit IgG or goat anti-mouse IgG, diluted 1:10,000 and 1:15,000, respectively, in $2.5 \%$ dry milk, $1 \times$ TBST. Antibody binding sites were revealed using an enhanced chemiluminescence (ECL) kit (Pierce, Rockford, IL, USA) and exposing membranes to the Hyperfilm ECL (GE Healthcare, Waukescha, WI, USA). Densitometric analysis of the immunopositve bands was performed using the ImageQuant 5.2 software (GE Healthcare). The optical density (OD) of each band, expressed as arbitrary gray units, was normalized against the OD of the GAPDH-positive band in the same lane, used as the internal reference protein. Densitometric values were expressed as the ratio of OD between MPTP and control mice.

In situ zymography

Gelatinolytic activity (MMP-9 and MMP-2) in SNpc and striatum of control and MPTP-treated (72 h) C57BL/6J mice was evaluated by in situ zymography on frozen brain sections. Animals were anesthetized with isoflurane and killed by decapitation, brains were rapidly removed, frozen on dry-ice and stored at $-80{ }^{\circ} \mathrm{C}$ until use. Coronal serial sections $(10 \mu \mathrm{m}$-thick) were cut at a cryostat, mounted on Super Frost Ultra Plus ${ }^{\circledR}$ glass slides (Menzel-Gläser, Braunschweig, Germany) and incubated overnight at $37{ }^{\circ} \mathrm{C}$ in a gelatinase activation buffer composed by $50 \mathrm{mM}$ Tris/ $\mathrm{HCl}$ (pH 7.6), $150 \mathrm{mM} \mathrm{NaCl}, 5 \mathrm{mM} \mathrm{CaCl}_{2}, 0.2 \mathrm{mM} \mathrm{NaN} 3$ e $50 \mu \mathrm{g} / \mathrm{ml}$ of $\mathrm{DQ}^{\mathrm{TM}}$ Gelatin from Pig Skin FluoresceinConjugated (Molecular Probes, Eugene, OR, USA). Negative controls were obtained by adding $20 \mathrm{mM}$ EDTA to the activation buffer. Before being coverslipped with Prolong $^{\circledR}$ Gold anti-fade reagent (Invitrogen), sections were post-fixed (30 min at RT) with $4 \%$ formalin in phosphate buffered saline (PBS) and nuclei counterstained with diamidino-2-phenylindole (DAPI) (1:1,000, Invitrogen). Sites of proteolytic activities, visible as a fluorescent emission consequent to gelatin enzymatic cleavage by MMPs, were observed with a Zeiss Axioplan 2 microscope.

Immunohistochemistry, immunofluorescence and confocal analysis

\section{Primary antibodies}

Sheep anti-TH $(1: 1,000)$, mouse anti-NeuN (1:500), mouse anti-glial fibrillary acid protein (GFAP, 1:500) and rabbit anti-MMP-9 (1:1,000) were from Chemicon. Rabbit antiIba-1 (1:500) was from Wako (Chuo-Ku, Osaka, Japan).

\section{Animal treatment}

Mice $\mathrm{C} 57 \mathrm{BL} / 6 \mathrm{~J}$ mice, $\mathrm{B} 6 . \mathrm{FVB}(\mathrm{Cg})-M m p 9^{t m 1 T v u} / \mathrm{J}$ mice, and their matching WT mice were deeply anesthetized with an i.p. injection of ketamine ( $50 \mathrm{mg} / \mathrm{kg}$ body weight) and xylazine $(50 \mathrm{mg} / \mathrm{kg}$ body weight), and perfused transcardially with an oxygenated Ringer solution ( $\mathrm{pH} 7.3)$, followed by $4 \%$ freshly depolymerized paraformaldehyde (PFA) in $0.1 \mathrm{M}$ phosphate buffer (PB) (pH 7.4). Brains were removed and cryoprotected in $30 \%$ sucrose, at $4{ }^{\circ} \mathrm{C}$, until they sank. Free-floating coronal serial sections (25 $\mu \mathrm{m}$-thick) were cut at a cryostat and stored in cryoprotectant (ethylene glycol: $0.2 \mathrm{M} \mathrm{PB}, \mathrm{pH} 7.4$ in a $1: 1$ proportion, with addition of $0.5 \mathrm{M}$ sucrose) at $-20{ }^{\circ} \mathrm{C}$ until use. Experimental groups and times after MPTP treatment were the following: C57BL/6J (control, 24, 48, $72 \mathrm{~h}, 1$ and 2 weeks after MPTP injection), B6.FVB $(\mathrm{Cg})-M m p 9^{t m 1 T v u} / \mathrm{J}$ mice and their matching WT (control, $72 \mathrm{~h}$ and 2 weeks after MPTP injection).

\section{Macaques}

Macaques were killed by a lethal injection of pentobarbital after a pre-anesthesia with ketamine $(8 \mathrm{mg} / \mathrm{kg}$ body 
weight). Brains were rapidly removed, fixed for 3 days in $4 \%$ freshly depolymerized PFA in $0.1 \mathrm{M} \mathrm{PB} \mathrm{(pH} \mathrm{7.4)} \mathrm{and}$ sectioned into coronal $40 \mu \mathrm{m}$-thick serial sections at a vibratome (Barcia et al. 2004).

\section{Immunofluorescence}

Localization of MMP-9 by immunofluorescence was enhanced using the Renaissance ${ }^{\circledR}$ Tyramide Signal Amplification (TSA)-biotin system kit (PerkinElmer), according to the manufacturer's instructions. After antigen retrieval with citrate buffer $(\mathrm{pH} 6.0)\left(30 \mathrm{~min}\right.$ at $\left.65^{\circ} \mathrm{C}\right)$ and quenching of the endogenous peroxidase activity, sections were incubated ( $1 \mathrm{~h}$ at RT) in a TNB blocking buffer $(0.1 \mathrm{M}$ Tris/ $\mathrm{HCl} \mathrm{pH} 7.5,0.15 \mathrm{M} \mathrm{NaCl}, 0.5 \%$ blocking reagent by the manufacturer) and then $\left(48 \mathrm{~h}\right.$ at $\left.4{ }^{\circ} \mathrm{C}\right)$ with the rabbit anti-MMP-9 antibody in combination with one of the other primary antibodies (see above), diluted in TNB blocking buffer. Amplification of the signal was obtained by incubation (30 min at RT) with a biotinylated goat anti-rabbit IgG secondary antibody (1:100, Vector Labs, Burlingame, CA, USA), diluted in TNB blocking buffer, followed by streptavidin-HRP conjugate (SA-HRP) $(1: 100,30 \mathrm{~min}$ at RT), and finally by a biotinyl tyramide working solution (1:50 Biotinyl Tiramide Stock Solution diluted in $1 \times$ Amplification Diluent, $10 \mathrm{~min}$ at RT). Amplification was blocked by rinsing the sections in TNT buffer, and antibody-antigen binding sites were revealed by a $30 \mathrm{~min}$ incubation in the SA-Fluorescein conjugate (1:500 in TNB), followed by the appropriate secondary antibody conjugated with either Alexa Fluor 633 or Alexa Fluor 594 (1:1,000) (Molecular Probes, Carlsbad, CA, USA). DAPI was used for nuclear staining and sections were collected on glass slides and coverslipped with the Prolong ${ }^{\circledR}$ Gold reagent.

In mice, presence of MMP-9 in microglial cells was ascertained by MMP-9 immunolabeling followed by a staining with the widely used rhodamine-conjugated tomato lectin, Griffonia Simplicifolia Lectin I (GSA) (Vector Labs) diluted 1:100 (Pott Godoy et al. 2008).

\section{Confocal analysis}

Fluorescent specimens were viewed under a Leica DMIRE2 confocal microscope (Leica Microsystems, Wetzlar, Germany) with a $63 \times$ immersion-oil objective, except for the MMP-9/tomato lectin localization, which was analyzed at the Zeiss Axioplan 2 microscope, as fluorescence faded rapidly under the laser beam. Acquired images were analyzed with the Leica Confocal Software. To avoid cross talk between the fluorophores, we carefully adjusted the spectral ranges of detectors and scanned images sequentially. Each section was scanned in $0.5 \mu \mathrm{m}$ thick optical sections, the series range being determined by setting the upper and the lower thresholds with the $Z / Y$ position for spatial image series setting. Images are presented as a transparency of all layers merged together. For further details see Barcia et al. (2008).

\section{Immunohistochemistry}

Endogenous peroxidase was inhibited $\left(0.3 \% \mathrm{H}_{2} \mathrm{O}_{2}\right.$ and $10 \%$ methanol in PBS, for $15 \mathrm{~min}$ at RT) and then antigen retrieval was performed as described above. After a prepermeabilization with $1 \%$ Triton X-100, non-specific antibody binding sites were blocked in $10 \%$ normal horse serum (NHS) in 0.1 M PBS (60 min at RT), and then slices were incubated $\left(48 \mathrm{~h}\right.$, at $\left.4{ }^{\circ} \mathrm{C}\right)$ with the anti-TH primary antibody, diluted in $1 \%$ NHS, $0.5 \%$ Triton X-100, $0.1 \%$ $\mathrm{NaN}_{3}$ and PBS, followed by a biotinylated donkey antisheep IgG (Jackson Immuno Research) (1:500, for $2 \mathrm{~h}$ ), and then the avidin-biotin-peroxidase complex $(1: 100$, $30 \mathrm{~min}$ at RT) (ABC Vectastain Elite kit, Vector Labs). Antibody binding sites were revealed by incubating the

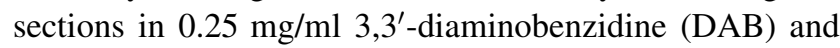
$0.03 \% \mathrm{H}_{2} \mathrm{O}_{2}$ in PBS (10 min at RT). Negative controls were obtained by omitting the primary antibodies. Sections were mounted on gelatin-coated slides, dehydrated in a series of ethyl alcohols and xylene, dried and permanently coverslipped with Eukitt mounting medium (Kindler GmbH, Freiburg, Germany).

\section{Cresyl violet staining}

Three random sections of the $\mathrm{SN}$ from each of the series used for immunofluorescence of the MMP-9 knock-out mice, and their matching WT mice, were stained with $1 \%$ cresyl violet for $2 \mathrm{~min}$. Following dehydration in a series of ethyl alcohol and xylene, sections were dried and permanently coverslipped with Eukitt mounting medium. Stereological quantification of the SNpc neurons was performed as detailed in the next section.

Quantitative analysis

\section{Immunohistochemistry}

Number of $\mathrm{TH}^{+}$neurons in the $\mathrm{SN} p c$ and densitometric value of $\mathrm{TH}$ immunolabeling in the striatum, as well as number and area of $\mathrm{GFAP}^{+}$and $\mathrm{Iba}^{+}$cells in both $\mathrm{SN} p c$ and striatum of MMP-9 knock-out mice, revealed by the ABCDAB method, were estimated on three representative sections per each mouse brain series. Sections were viewed at a Zeiss Axioplan 2 light microscope connected to a digital camera (AxioCam HRc, Zeiss). Images of (SNpc) and striatum were acquired by using a $20 \times$ and $1.25 \times$ objectives, respectively. Density of immunopositive cells per area was 
expressed as the number of cells $/ \mathrm{mm}^{2}$. TH immunolabeling in the striatum was determined by the ImageJ software as optical density (OD) values and was considered as an index of the density of DA innervation. The area $\left(\mu \mathrm{m}^{2}\right)$ occupied by microglia and astrocytes (including both cell bodies and processes), identified by specific labeling, was considered an index of glial cell activation and was expressed as both total and mean area occupied by immunopositive cells per photographic field. Mean cell area values were obtained by dividing the total area covered by immunopositive cells for their number. All data were generated using the ImageJ software for image analysis. All quantifications were performed blindly.

\section{Immunofluorescence}

Three representative sections of the $\mathrm{SN} p c$ and striatum of each control and MPTP-treated mice, and 2 from each control and parkinsonian macaque striatum, were chosen and 3 random images were captured from both sides of sections. Cells immunopositive for both MMP-9 and one of the cell markers used were counted only when the area of co-localization was detected in the majority of the $0.5 \mu \mathrm{m}$ thick optical layers throughout the entire stack. The number of single and double immunolabeled cells was quantified on the best of the single $0.5 \mu \mathrm{m}$-thick optical sections, and results were expressed as the number of immunopositive cells $/ \mathrm{mm}^{2}$. All quantifications were done blindly.

\section{Statistical analysis}

Data were analyzed using either the one-way ANOVA test following the post hoc Dunnet's test (adequate for multiple comparisons against a single reference group) or the two-tail Student's $t$ test (which compares two groups at a time). Differences were considered statistically significant for $p \leq 0.05$. Data were expressed as the mean \pm standard error of the mean (SEM). A Pearson coefficient was used for the correlation analysis and its significance was determined using the critical values of the Pearson coefficient table. Differences were considered statistically significant for $p \leq 0.05$.

\section{Results}

MMP-9 mRNA and protein levels are modulated in the nigro-striatal pathway by acute MPTP treatment in mice

mRNA levels for MMP-9 (gelatinase B) were investigated by real-time RT-PCR. Based on previous studies (Annese et al. 2013), we explored a time window after the last MPTP injection that spanned the entire period of DA neuron degeneration and the partial recovery of those who escaped death, along with the rising and subsiding of neuroinflammatory events (Hirsch and Hunot 2009). MMP9 mRNA was significantly and consistently induced, in both SN (Fig. 1a) and striatum (Fig. 1b), at different times after acute MPTP administration. mRNA levels were upregulated $(+1.8$ folds, $\mathrm{SN} ;+2.2$ folds, striatum) by $24 \mathrm{~h}$ after the last MPTP injection, remaining significantly higher than control in the following $48 \mathrm{~h}(+2.5$ folds, $S N)$ (Fig. 1a) and 1 week (+1.2 folds, striatum) (Fig. 1b).

MMP-9 protein levels were investigated by Western immunoblot in SN and striatum homogenates of control and parkinsonian mice, killed at the same post-treatment time as indicated above. The MMP-9 antibody revealed two bands of about $97 \mathrm{kDa}$ (pro-MMP-9) and $92 \mathrm{kDa}$ (active MMP-9) (Fig. 1c, SN; Fig. 1d, striatum). A human recombinant MMP-9, used as positive control and loaded on a separate lane in the same gels, appeared as a single band corresponding to the active MMP-9, and migrated slightly below its homologous in the mouse brain homogenates. Densitometric analysis of the immunopositive bands revealed that, similar to mRNA, protein levels of both pro- and active MMP-9 increased significantly by $24 \mathrm{~h}$ (Fig. 1c $\mathrm{c}^{\prime}, \mathrm{SN}$ ) and $1 \mathrm{~h}$ (Fig. 1d $\mathrm{d}^{\prime}$, striatum) after MPTP administration, remaining higher than control throughout the post-treatment time considered. The apparent discrepancy in the post-injection times, at which we observed the main changes in MMP-9 mRNA and protein levels is a common event, especially for MMPs since these proteins are subjected to a prominent post-transcriptional control.

MMP-9 immunolocalization and quantitative analysis in control and MPTP-treated mice

The persistent and significant increase in MMP-9 protein levels in the SN and striatum of MPTP-treated mice involved both the inactive pro-enzyme and its active form (post-translationally activated). However, this analysis did not allow the identification of the type/s of cells expressing MMP-9 in control conditions. Moreover, this preliminary observation did not show changes in MMP-9 distribution after MPTP treatment and, less than that, whether and how active MMP-9 intervenes in: (a) MPTP-induced DA neuron death in the SN and (b) the neuroinflammatory process to which neurodegeneration associates. Therefore, we performed a confocal study, combined with quantitative analysis, for MMP-9 immunopositive $\left(\mathrm{MMP}^{+} \mathrm{9}^{+}\right)$cell localization in control and MPTP-treated mice. Brain sections were immunolabeled for MMP-9 alone or in combination with different cell typespecific markers: NeuN (neurons), TH (DA neurons), GSA (microglia) and GFAP (astrocytes).

Before this, we carried out both gelatin zymography (on $\mathrm{SN}$ and striatum tissue extracts) and in situ zymography 

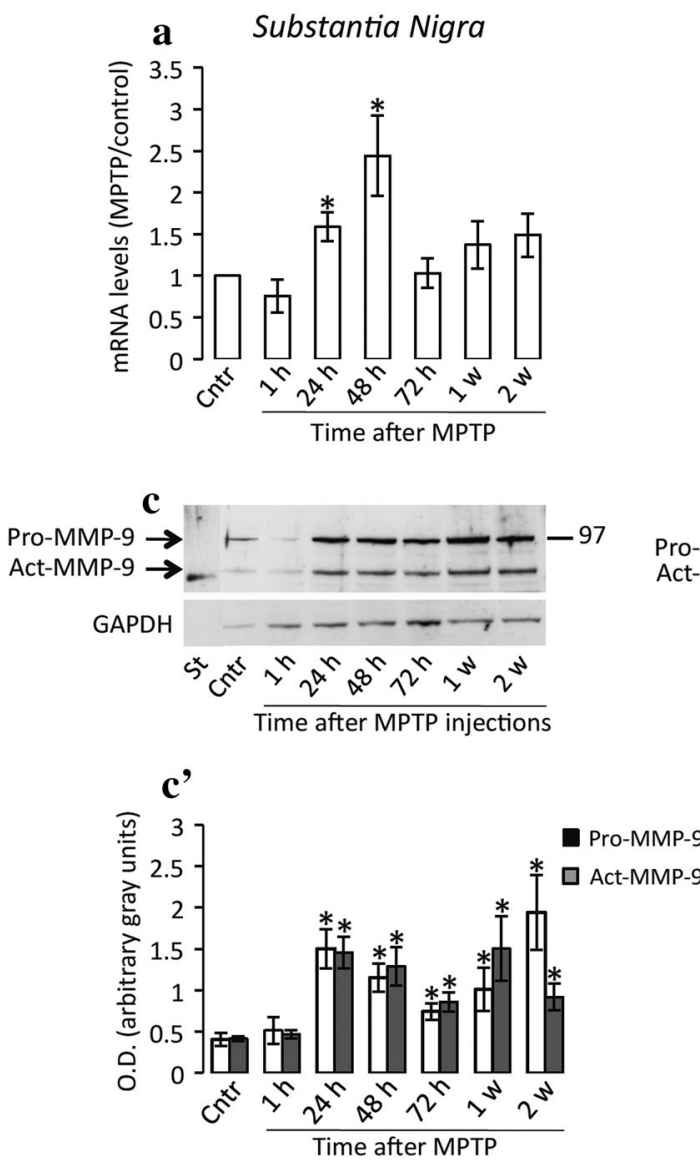
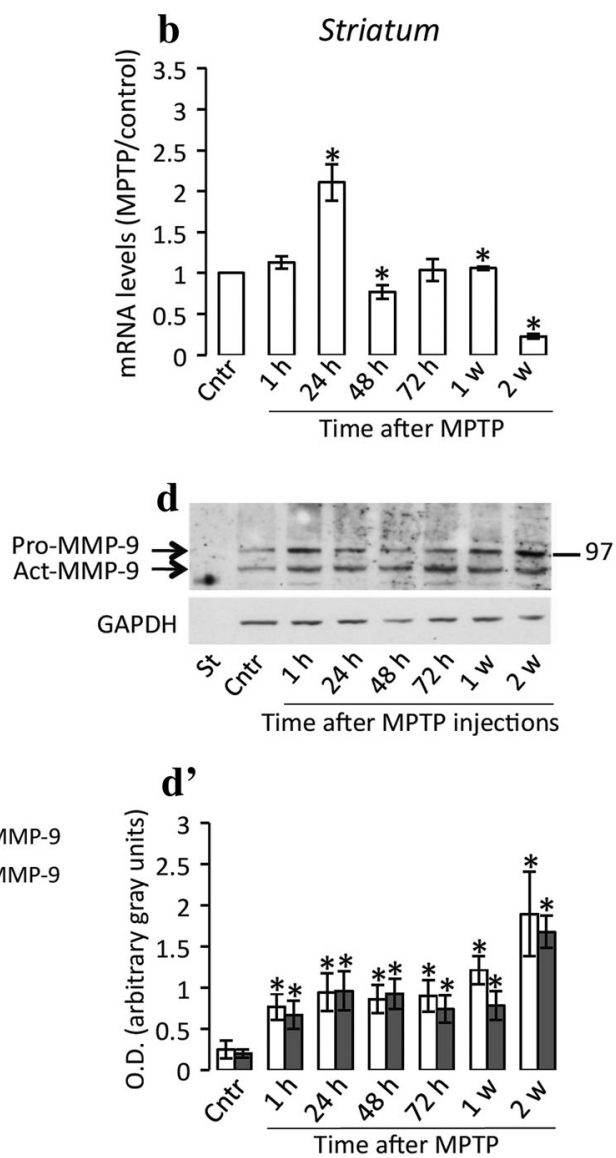

Fig. 1 MMP-9 mRNA and protein levels increase in both substantia nigra (SN) and striatum after MPTP treatment. MMP-9 mRNA levels in control and MPTP-treated mice. MMP-9 mRNA levels increase significantly, compared to control (Cntr), within $24 \mathrm{~h}$ after the last MPTP injection in both SN (a) and striatum (b). However, while in the SN we observe a further increase after $48 \mathrm{~h}$ and then a decrease towards Cntr levels, in the striatum MMP-9 mRNA decreases significantly below Cntr, until the 2 weeks time point. $n=8$ mice/ experimental group. Data are represented as the mean \pm SEM. of mRNA levels in MPTP-treated mice/control. c-d' MMP-9 Western immunoblot and relative quantitative analysis in control and MPTPtreated mice. Typical MMP-9 Western immunoblot in the SN (c) and striatum (d). MMP-9 antibody recognized two bands at the predicted

(on brain sections), to verify the presence of MMP-9 activity in control and $72 \mathrm{~h}$ MPTP-treated mice (chosen as a representative post-injection time point). Gelatin zymography is a poorly sensitive and quite variable technique, and the signal we obtained from both $\mathrm{SN}$ and striatum was too low to be properly quantified (see also Lorenzl et al. 2004 on pools of entire midbrain extracts). In situ zymography, instead, showed that in both brain areas, MPTP treatment elicited an increase in cellular and extracellular fluorescent signal when compared to control (Fig. 2). Since the other gelatinase (gelatinase A, MMP-2), differently from MMP-9, is scarcely detectable at the protein level both before and after MPTP treatment molecular mass of the pro- (100 kDa) and active (92 kDa) MMP-9. The recombinant human MMP-9 used as standard (St) migrates at a slightly lower molecular mass with respect to the mouse active MMP9. GAPDH was used as the internal reference protein. $\mathbf{c}^{\prime}, \mathbf{d}^{\prime}$ Densitometric analyses of the immunopositive bands reveal an early and significant increase, compared to control, in the protein levels of both pro- and active MMP-9, $24 \mathrm{~h}(\mathrm{SN})$ and $1 \mathrm{~h}$ (striatum) after MPTP injection. Protein levels remain significantly higher than control throughout the post-injection time considered. $O D$ optical density. $n=8$ animals/experimental group. Data are represented as the mean \pm SEM of OD in MPTP-treated mice/control. ${ }^{*} p \leq 0.05$, calculated by one-way ANOVA and Duncan's test

(unpublished observation), we hypothesized that most of this labeling was generated by gelatinase $\mathrm{B}$ activation.

Confocal microscopy studies were performed on control and MPTP-treated mice killed 24, 48, $72 \mathrm{~h}$ and 2 weeks after the last toxin injection. Data will be presented subdivided by cell type (neuron, microglia, astrocytes).

\section{MMP-9/NeuN/TH and MMP-9/NeuN co-localization} in the SNpc and striatum of control and MPTP-treated mice

To ascertain whether MMP-9 was synthesized by DA neurons in the $\mathrm{SN} p c$ and whether this expression changed 
Fig. 2 Gelatinolytic activity increases in the $\mathrm{SN}$ and striatum of MPTP-treated mice compared to control. Representative brain cryosections showing an increase, with respect to control, in both number of labeled cells and intensity of the fluorescent signal of MMP-9 gelatinolyitc activity after MPTP treatment, obtained by in situ zimography. Lines are to guide the eye in SN demarcation. Scale bar $100 \mu \mathrm{m}$
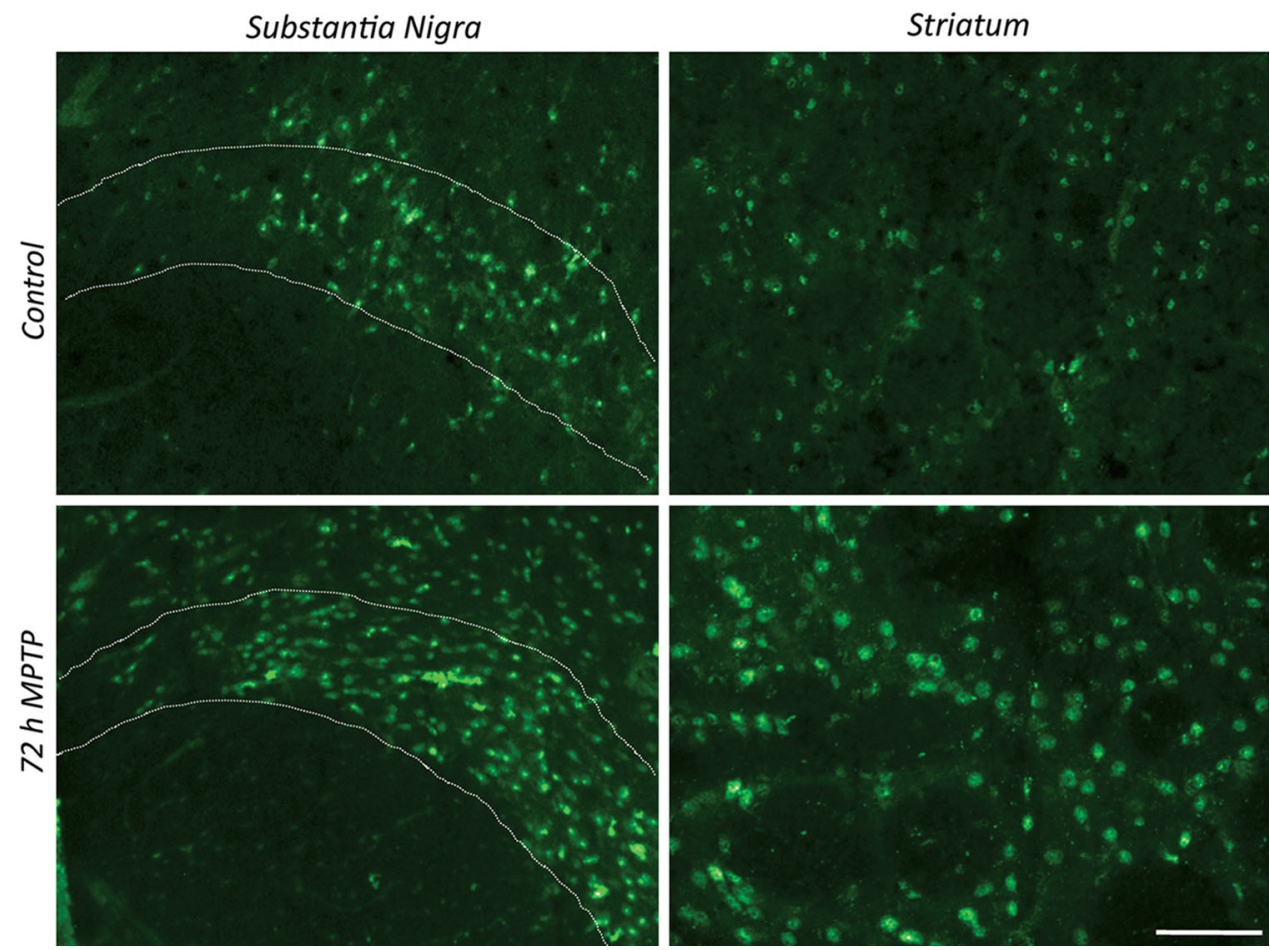

after MPTP administration, we performed a triple immunofluorescence, by combining anti-MMP-9 with both NeuN and TH immunolabeling. As shown in Fig. 3a, MMP-9 largely co-localized with NeuN and TH, in both control and Parkinsonian mouse brain sections, intensely decorating cell bodies and axons. Extracellular dots of immunoreactivity were also observed, likely representing transversally cut axons and/or secreted MMP-9. Quantitative analysis of the immunopositive cells showed that numerous $\mathrm{NeuN}^{+}$cells expressed MMP-9 (Fig. 3a'). Among these, a large part of $\mathrm{TH}^{+}$neurons were also MMP$9^{+}$(Fig. 3a'), and the majority of $\mathrm{NeuN}^{+}$neurons were DA $\left(\mathrm{TH}^{+}\right)\left(\right.$Fig. $\left.3 \mathrm{a}^{\prime \prime}\right)$, in both control and Parkinsonian mice. As expected, MPTP-treatment determined a significant decrease in MMP-9 ${ }^{+}$cells within the following $24 \mathrm{~h}$ (Fig. $3 \mathrm{a}^{\prime}$ ); this coincided with a significant decrease in the total number of neurons $\left(\mathrm{NeuN}^{+}\right.$in Fig. $\left.3 \mathrm{a}^{\prime}\right)$ and $\mathrm{TH}^{+}$ neurons (Fig. $3 \mathrm{a}^{\prime \prime}$ ), both alone and in co-localization with MMP-9, clearly noticeable also in the confocal images (Fig. 3a). The number of all immunopositive cells (MMP$9^{+}, \mathrm{NeuN}^{+}, \mathrm{NeuN}^{+} / \mathrm{MMP}^{-}{ }^{+}, \mathrm{TH}^{+}$and $\mathrm{TH}^{+} / \mathrm{MMP}^{-}{ }^{+}$) partially, but significantly, recovered 2 weeks after MPTP administration (Fig. $3 \mathrm{a}^{\prime}, \mathrm{a}^{\prime \prime}$ ). This pattern was further verified in the second part of this work (conducted on MMP-9 $\mathrm{KO}$ mice) and confirmed by a parallel study, in which $\mathrm{TH}^{+}$ neurons, revealed by the immuno-enzymatic method of the HRP-DAB, were counted in SNpc sections, serial to those used in this study (Annese et al. 2013). Changes in TH protein levels in the $\mathrm{SN}$ were also quantified by
Fig. 3 MMP-9 is mainly neuronal in both control and MPTP-treated mice, but the number of immunopositive neurons is differently modulated along the nigro-striatal pathway. Confocal images of MMP-9 co-immunolabeling with NeuN and TH in the substantia nigra pars compacta (SNpc) and striatum of control and MPTPtreated mice (72 $\mathrm{h}$ after MPTP injection) and relative quantitative analyses. a MMP-9 (green) co-localizes with both NeuN (purple) and TH (red) in SNpc sections of control and parkinsonian mice. MMP-9 largely localizes in dopaminergic neurons, labeling both cell bodies and axons (arrow in the merge panel). However, the few nondopaminergic neurons present in the $\mathrm{SN} p c$ are also immunopositive (arrowhead in the merge panel). Nuclei are stained in blue with DAPI. Scale bar $25 \mu \mathrm{m}$. $\mathbf{a}^{\prime}$ The number of MMP-9 $9^{+}$(black bars), $\mathrm{NeuN}^{+}$(gray bars) and $\mathrm{NeuN}^{+} / \mathrm{MMP}^{-}{ }^{+}$(white bars) cells undergoes a significant decrease, with respect to control (Cntr), $24 \mathrm{~h}$ after MPTP treatment, followed by a partial, but significant recovery (with respect to the $72 \mathrm{~h}$ time point) after 2 weeks. $\mathbf{a}^{\prime \prime}$ The number of $\mathrm{TH}^{+}$ (black bars), $\mathrm{TH}^{+} / \mathrm{MMP}^{-}{ }^{+}$(gray bars) cells follows the same time course described for the SN. Differently, the number of $\mathrm{NeuN}^{+} / \mathrm{TH}^{-}$ (white bars) does not change and that of $\mathrm{NeuN}^{+} / \mathrm{MMP}^{-} 9^{+} / \mathrm{TH}^{-}$ (white-black bars) cells increases slightly, but significantly, $72 \mathrm{~h}$ after MPTP treatment. b MMP-9 (green) largely co-localizes with NeuN (purple) in sections of striatum from control and parkinsonian mice (arrows in the enlarged boxed area), although not all neurons are MMP- $9^{+}$(arrowhead in the enlarged boxed area). Nuclei are stained in blue with DAPI. Scale bar low magnification, $40 \mu \mathrm{m}$; enlarged boxed area, $10 \mu \mathrm{m}$. $\mathbf{b}^{\prime}$ The number of MMP- $9^{+}$cells (black bars) increases significantly with respect to Cntr by $48 \mathrm{~h}$ after MPTP injection, remaining higher up to 2 weeks. Differently, the number of neurons, either expressing MMP-9 $\left(\mathrm{NeuN}^{+} / \mathrm{MMP}^{-} 9^{+}\right)$(white bars) or not $\left(\mathrm{NeuN}^{+}\right)$(gray bars) does not change. $n=4$ animals/experimental group. For all quantitative analyses, data are represented as the mean \pm SEM of the cell number/mm ${ }^{2} . * p \leq 0.05$ (MPTP vs. Cntr); ${ }^{\wedge} p \leq 0.05$ ( 2 weeks vs. $72 \mathrm{~h}$ MPTP) calculated by one-way ANOVA and Duncan's test 
a

\section{Substantia Nigra}

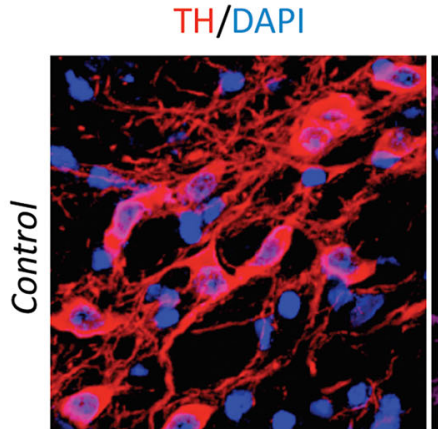

NeuN/DAPI

MMP-9/DAPI

Merge
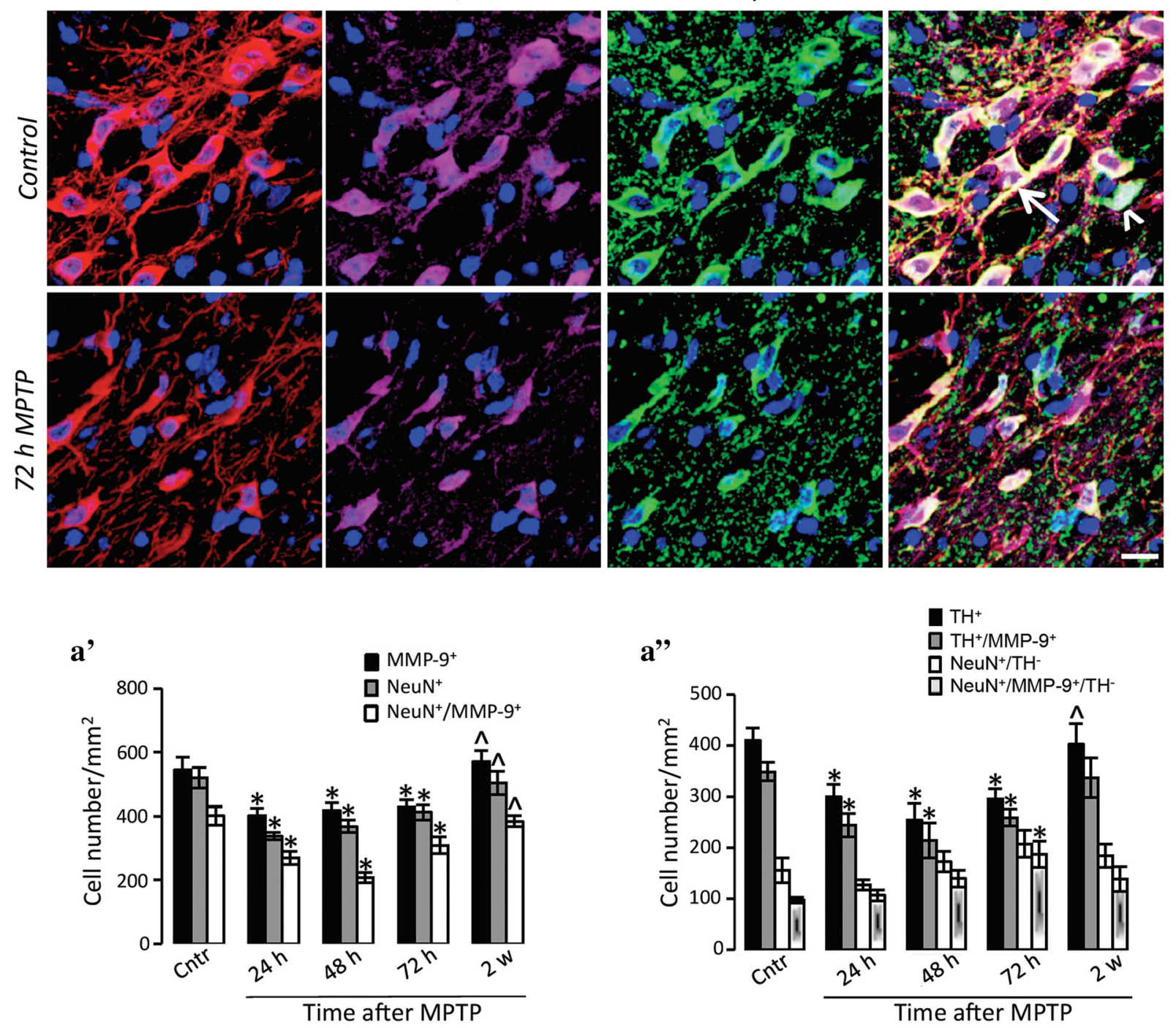

Striatum

b

MMP-9/DAPI
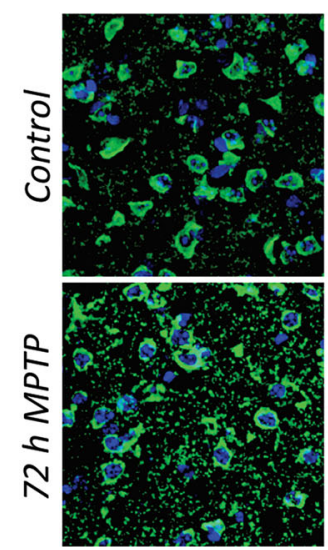

NeuN/DAPI

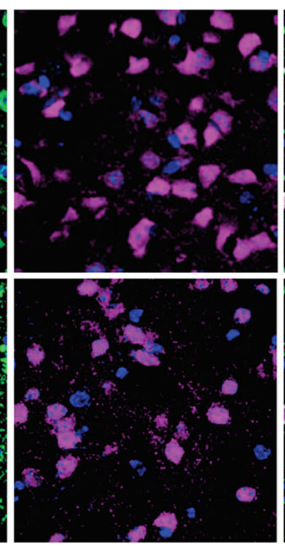

Merge

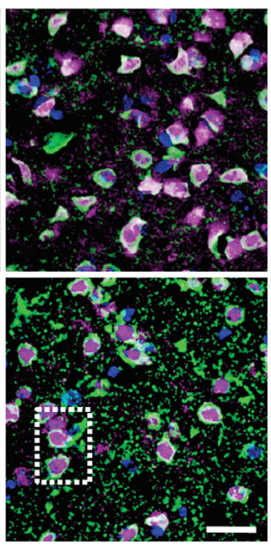

b'

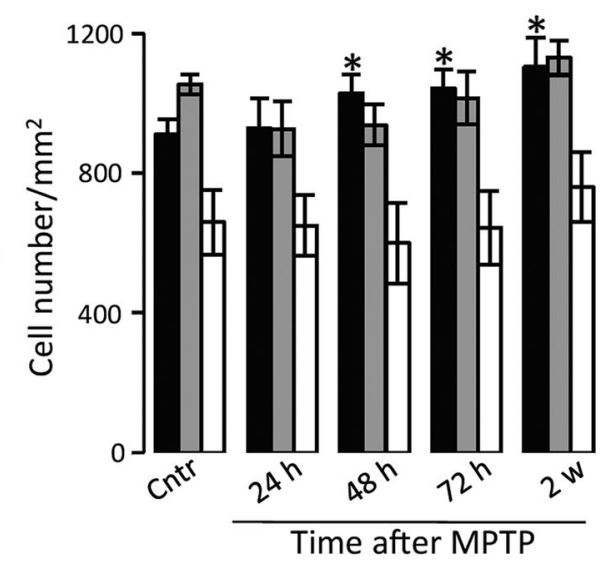



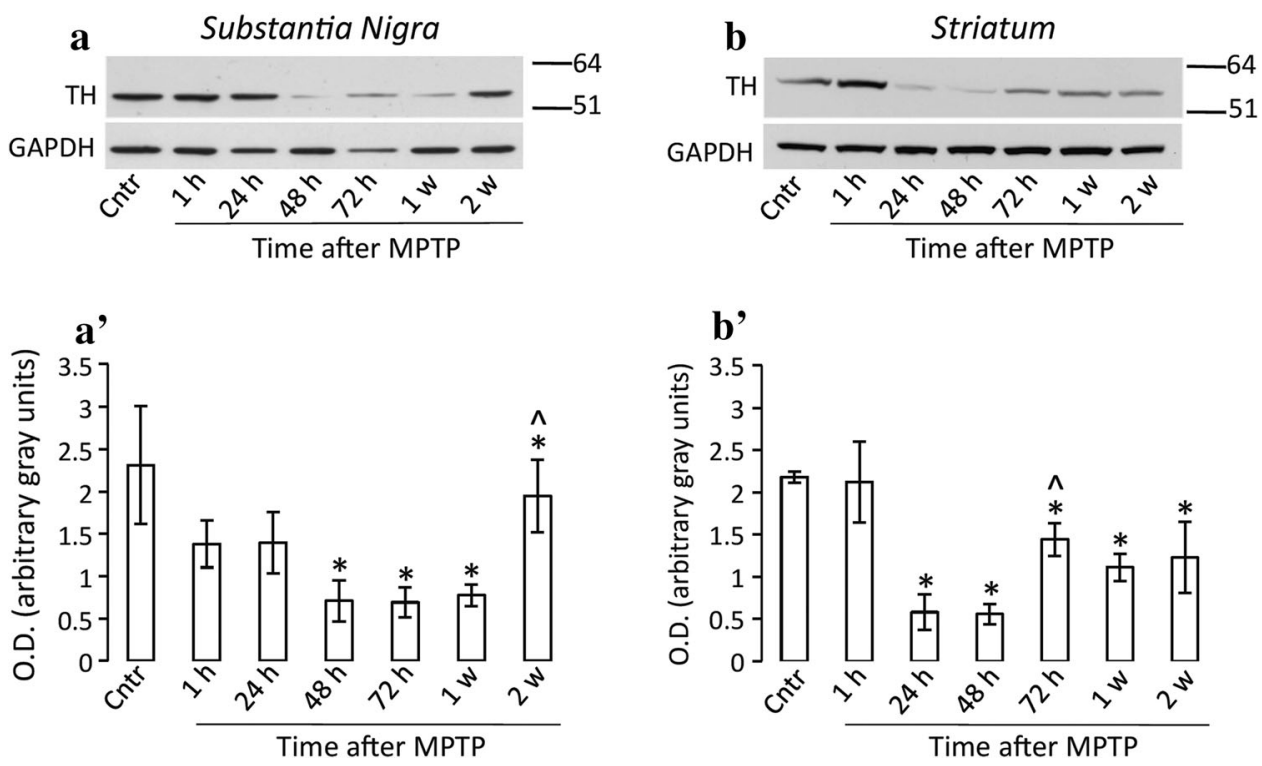

Fig. 4 Time course of the changes in TH protein levels in both substantia nigra $(\mathrm{SN})$ and striatum of MPTP-treated mice. Typical Western immunoblots revealing levels of TH on protein extracts from the SN (a) and striatum (b) of control (Cntr) and MPTP-treated mice, from $1 \mathrm{~h}$ to 2 weeks post-injection. The anti-TH antibody recognizes a single band of about $62 \mathrm{kDa}$. The intensity of the band decreases after MPTP treatment, with respect to Cntr, and partially recovers after 2 weeks. GAPDH is used as the internal reference protein.

densitometric analysis of Western immunoblot (Fig. 4a, a') and results were in accordance with what was shown by immunohistochemistry.

From this quantitative study, it also emerged that the number of non-DA neurons $\left(\mathrm{NeuN}^{+} / \mathrm{TH}^{-}\right)$remained stable after MPTP treatment (Fig. $3 \mathrm{a}^{\prime \prime}$ ), indicating that the toxin does not affect this type of neurons in the SNpc. Moreover, the number of non-DA neurons expressing MMP-9 $\left(\mathrm{NeuN}^{+} / \mathrm{MMP}^{-}{ }^{+} / \mathrm{TH}^{-}\right)$increased slightly, but significantly, $72 \mathrm{~h}$ after the last MPTP injection (Fig. 3a"), suggesting that factors, possibly released by dying and/or suffering DA neurons, as well as by other types of cells, may trigger MMP-9 expression in the surrounding neurons.

Similar to the SNpc, MMP-9 immunolabeling in the striatum largely co-localized with NeuN, although not all neurons were MMP- ${ }^{+}$and not all MMP- $9^{+}$-cells were neurons (Fig. 3b). Seventy-two hours after the last MPTP injection, a clear increase in MMP-9 immunolabeling was observed. Large part of the staining was visible outside the cell bodies, being present not only in the extracellular space, but also within the thin processes of non-neuronal cells (see ahead in "Results"), and into transversally cut axons crossing the striatum (Fig. 3b). Quantitative analysis showed that the number of MMP- $9^{+}$cells increased significantly, with respect to control, by $48 \mathrm{~h}$ after MPTP injection, remaining higher than control up to 2 weeks after (Fig. $3 b^{\prime}$ ). Contrarily, the number of neurons, both positive

Molecular mass standards, expressed in $\mathrm{kDa}$, are indicated on the right hand side. $\mathbf{a}^{\prime}, \mathbf{b}^{\prime}$ Densitometric analysis reveals a significant decrease in TH protein levels by $24 \mathrm{~h}$ (striatum) $-48 \mathrm{~h}$ (SN), which remain lower than control until the last time point examined. However, a partial recovery, more evident in the SN, is observed after 2 weeks. $O D$ optical density. $n=8$ mice/experimental group. Data are represented as the mean \pm SEM of OD of the immunopositive bands. $* p \leq 0.05$, calculated by one-way ANOVA and Duncan's test

$\left.\left(\mathrm{NeuN}^{+} / \mathrm{MMP}^{-}\right)^{+}\right)$and negative $\left(\mathrm{NeuN}^{+}\right)$for MMP-9, did not change after treatment, suggesting that the increase in MMP- $9^{+}$cells may depend on activated and/or newly migrated non-neuronal cells.

Concomitant to confocal analysis, we evaluated $\mathrm{TH}$ levels in the striatum of control and MPTP-treated mice by Western immunoblot. Figure $4 b, b^{\prime}$ shows that TH levels significantly decreased with respect to control, 24 and $48 \mathrm{~h}$ after MPTP treatment, being recovered in the following time points but remaining below the control values. This is in agreement with the results obtained by densitometric evaluation of $\mathrm{TH}$ immunolabeling performed on striatum sections adjacent to those utilized in this study (Annese et al. 2013), as well as on sections from WT and MMP-9 KO mice (see ahead in "Results").

\section{MMP-9/GSA co-localization in the SNpc and striatum of control and MPTP-treated mice}

Microglia, the brain immune resident cells, are main modulators of neuroinflammation. As reported in the Introduction, in both PD patients and MPTP animal models of Parkinsonism, microglia shift from "surveillant" to "active", modify their morphology, and acquire migratory and phagocyte capabilities, according to a well-described step-to-step response (Streit et al. 1999). Here, we investigated whether MMP-9 was expressed by microglia and 
whether this expression was modulated by acute MPTPtreatment. For this purpose, we combined MMP-9 immunolabeling with GSA staining, a classical marker for microglia, widely used in the literature to identify both resting and activated microglia (Streit and Kreutzberg 1987; Pott Godoy et al. 2008). The choice of GSA was dictated by a technical impediment when combining MMP9 and microglia immunolabeling protocols using the classical Iba-1 or F4-80 antibodies. MPTP-induced microgliosis was, however, subsequently confirmed and quantified in the following experiments conducted on WT and MMP9 KO mice (see ahead in "Results"). For the MMP-9/GSA analysis, we used a classical fluorescent microscope, as the rhodamine labeling was rapidly fading under the confocal beam. In both control $\mathrm{SN} p c$ and striatum, GSA staining was scanty, mainly associated with blood vessels and small cell processes (Fig. 5a, SNpc). The number of $\mathrm{GSA}^{+}$cells significantly and progressively increased from $24 \mathrm{~h}$ to $72 \mathrm{~h}$ after MPTP-treatment (Fig. 5a, a', quantitative analysis) and then significantly decreased (compared to the $72 \mathrm{~h}$ time point) after 2 weeks, although remained higher than control. In control mice, coexistence of GSA and MMP-9 $\left.\left(\mathrm{GSA}^{+} / \mathrm{MMP}^{+}\right)^{+}\right)$was rarely observed in both $\mathrm{SN} p c$ (Fig. 5a', quantitative analysis) and striatum (Fig. 5c, quantitative analysis). By $24 \mathrm{~h}$ after MPTP treatment, the number of $\mathrm{GSA}^{+} / \mathrm{MMP}^{-}{ }^{+}$cells significantly increased in both areas, with respect to control (SNpc: Fig. 5a', quantitative analysis; striatum: Fig. 5c, quantitative analysis), overlapping with the period of major loss of $\mathrm{TH}^{+}$neurons in the $\mathrm{SN} p c$ and decrease in $\mathrm{TH}^{+}$fibers in the striatum. Different from neurons, MMP-9 immunolabeling in $\mathrm{GSA}^{+}$ cells appeared in small discrete dots, possibly representing points of accumulation/release. Two weeks later, while in the $\mathrm{SN} p c$ the number of $\mathrm{GSA}^{+} / \mathrm{MMP}_{-} 9^{+}$cells returned to control levels, concomitantly with the partial recovery of $\mathrm{TH}^{+}$neurons, in the striatum it remained significantly higher than control.

\section{MMP-9/GFAP co-localization in the SNpc and striatum of control and MPTP-injected mice}

Since astrogliosis commonly follows microglia activation in neuroinflammatory processes, we evaluated MMP-9 expression in astrocytes by co-localizing it with the cellspecific marker GFAP. Confocal analysis showed that, after MPTP treatment, both SNpc (Fig. 5b) and striatum underwent prominent astrogliosis. The number of $\mathrm{GFAP}^{+}$ cells increased significantly after $24 \mathrm{~h}$ (Fig. 5b', SNpc; Fig. 5d, striatum), remaining higher than control up to 2 weeks. The number of astrocytes expressing MMP-9 $\left.\left(\mathrm{GFAP}^{+} / \mathrm{MMP}^{-}\right)^{+}\right)$increased with the same time course than the number of $\mathrm{GFAP}^{+}$cells. As for microglia, the number of double immunolabeled cells (Fig. 5b) represented only a small percentage of the whole MMP-9 ${ }^{+}$ cell population.

A summary of the changes in the percentage of the different MMP-9 ${ }^{+}$cell types, emerged from the confocal and quantitative analyses, is shown in the pie charts of Fig. 6. In control conditions, MMP-9 is mainly expressed by neurons, in both $\mathrm{SN} p c$ and striatum. The number of immunopositive glial cells increases significantly after MPTP treatment, concomitantly with microgliosis and astrogliosis, and remains higher than control up to 2 weeks. Sector indicated as "others" comprehend a category of mixed cells, not identified in this study. A large part of these cells are certainly represented by oligodendrocytes (unpublished observation), which undergo massive oligodendrogliosis (Annese et al. 2013). The rest could be blood-born immune cells crossing the damaged blood brain barrier, attracted by the inflammatory process; however, their identity needs to be properly investigated.

MMP-9 immunolocalization and quantitative analysis in control and parkinsonian macaques

The mouse model of Parkinsonism has the advantage of a fast analysis of the cellular and molecular processes related to the nigro-striatal pathway degeneration. On the other hand, the use of the chronic macaque model of MPTP administration is extremely important for a better understanding of the role of inflammatory processes in the longterm disease progression, more similar to what happens in humans. We had the opportunity to use sections of the striatum (both caudate and putamen) of previously studied macaques (Barcia et al. 2004, 2011). These samples were already well characterized for the loss of DA neurons and axons, as well as for microglia activation. Here, we evaluated MMP-9 expression, alone and in combination with some of the specific markers used above (NeuN, GFAP), in the striatum of both control and parkinsonian macaques (2 years after MPTP-induced stable Parkinsonism). Similar to mice, MMP-9 immunolabeling co-localized with the neuronal marker NeuN (Fig. 7a), although numerous MMP-9 ${ }^{-}$neurons were also present. MPTP treatment induced a clear up-regulation in MMP-9 immunolabeling in both areas with respect to control (Fig. 7a). Quantitative analysis confirmed a significant increase in both MMP-9 ${ }^{+}$ cells and NeuN ${ }^{+} / \mathrm{MMP}_{-} 9^{+}$labeled neurons (Fig. $7 \mathrm{a}^{\prime}$ ). The total number of $\mathrm{NeuN}^{+}$neurons, instead, remained comparable to control, suggesting that striatal neurons, previously immunonegative, were induced to express MMP-9 in parkinsonian primates. Numerous $\mathrm{MMP}_{-} 9^{+} / \mathrm{NeuN}^{-}$cells, with an apparent glial morphology and scarcely present in control monkeys, were also observed (Fig. 7a).

GFAP immunolabeling showed a dramatic and persistent astrogliosis in the striatum of MPTP-treated monkeys 


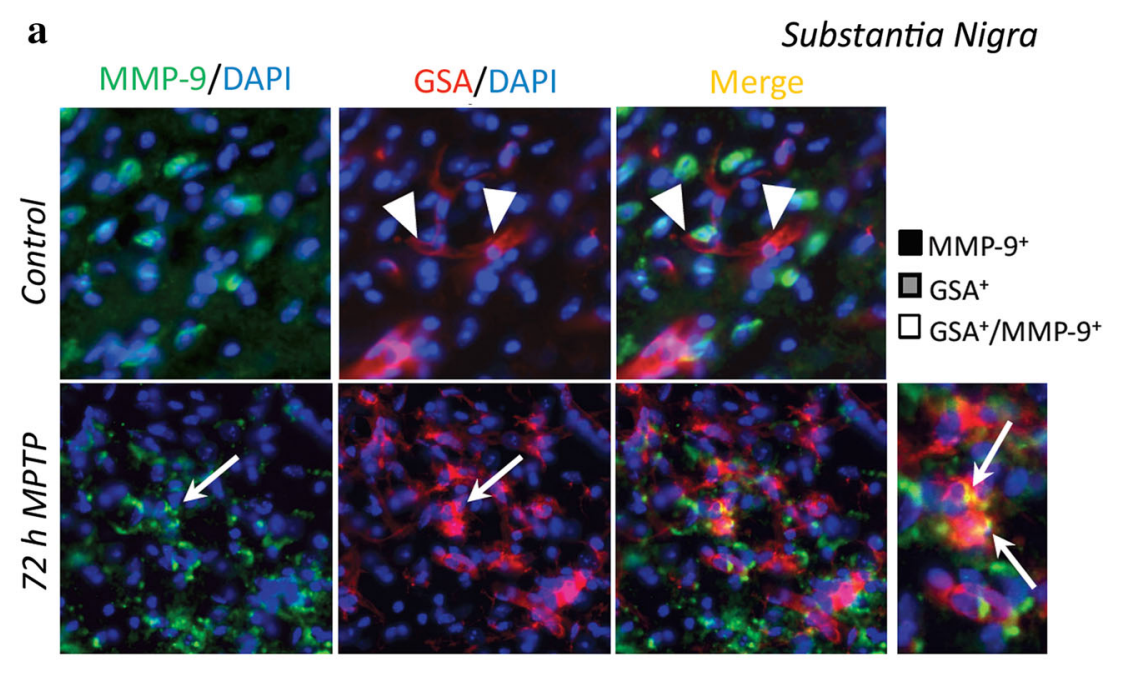

a'

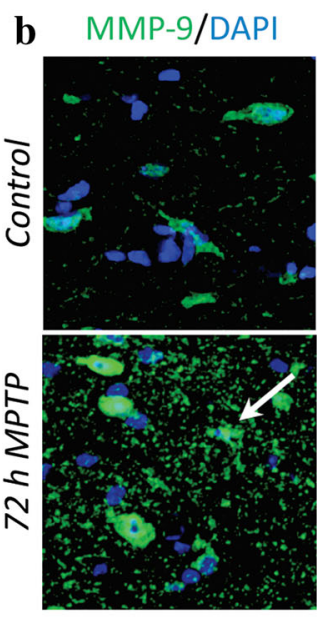

GFAP/DAPI

Merge
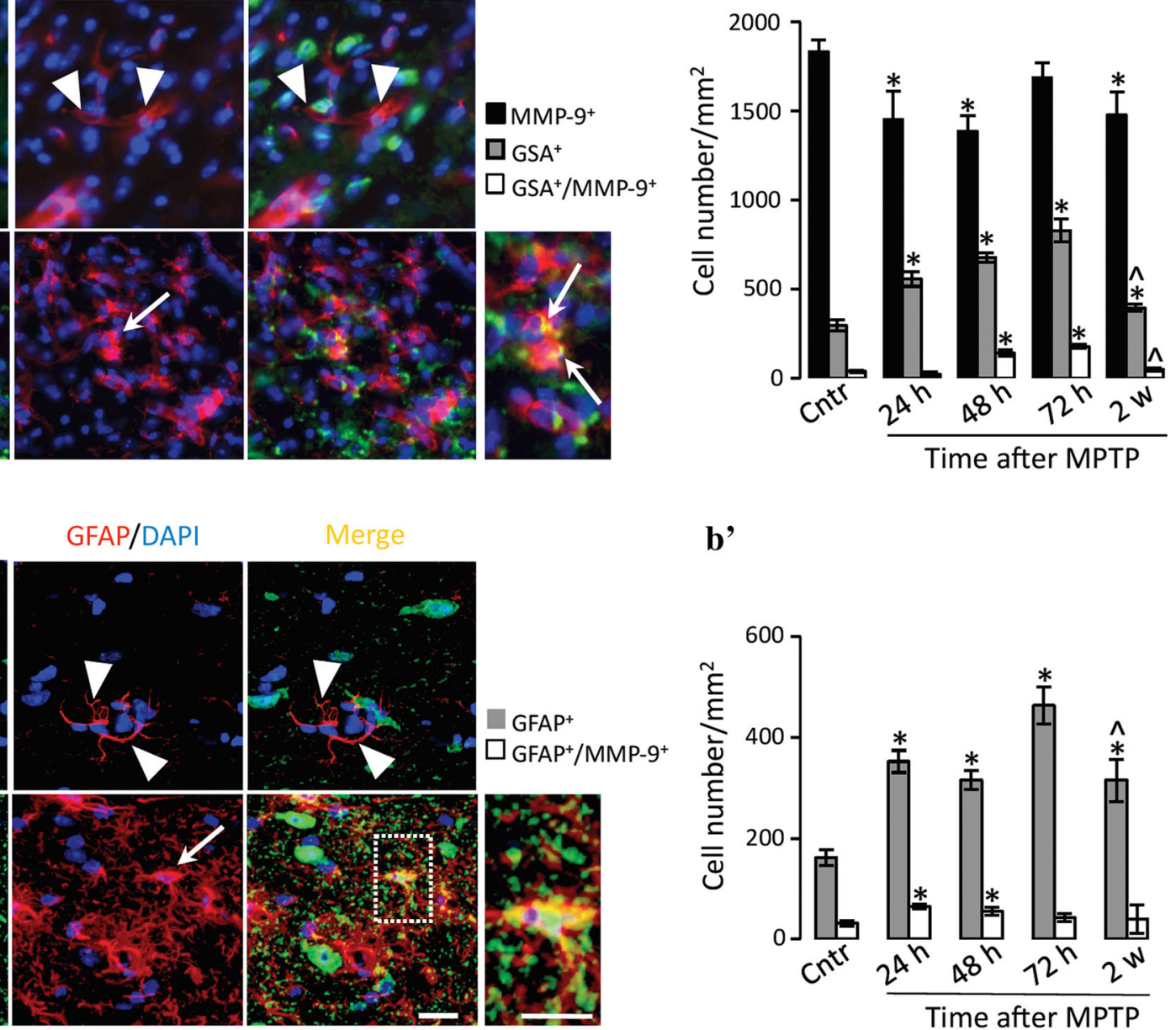

b'

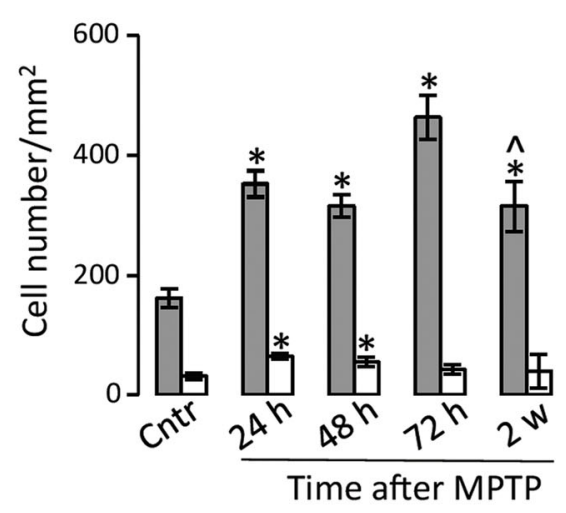

\section{Striatum}
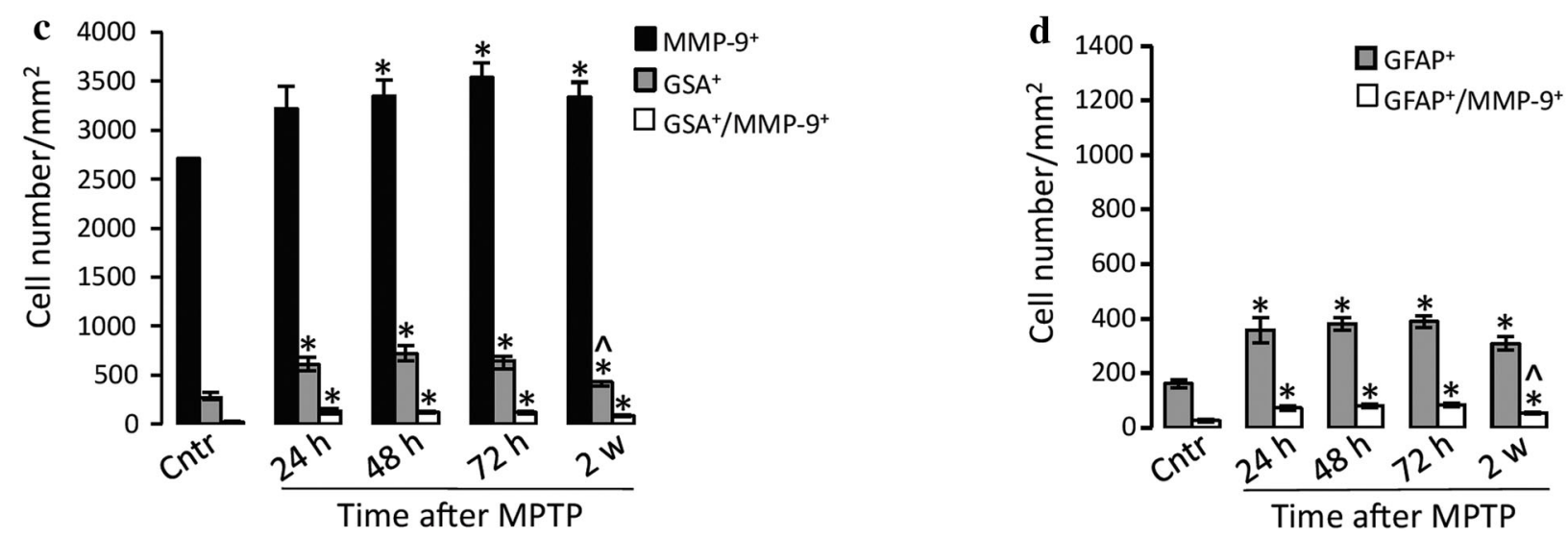

when compared to control animals (Fig. 7b). Astrocyte activation was characterized by an increase in cell size, as well as in the number and length of cell processes (Fig. 7b). GFAP/MMP-9 co-immunolabeling (MMP-9 ${ }^{+}$/
$\mathrm{GFAP}^{+}$) showed that astroglia represented only a small percentage of MMP- $9^{+}$cells, in both control and parkinsonian monkeys. However, after MPTP treatment, the number of MMP- $9^{+} / \mathrm{GFAP}^{+}$cells increased significantly 
४Fig. 5 MMP-9 expression by microglia and astrocytes significantly increase soon after MPTP treatment, concomitantly with a massive inflammatory response. Confocal study of MMP-9 co-labeling with GSA and GFAP in the substantia nigra pars compacta ( $\mathrm{SNpc}$ ) and striatum of control and MPTP-treated mice and relative quantitative analyses. a In the SNpc of control mice, GSA (red) staining labeled microglia cell bodies and thin processes (arrowheads). MMP-9/GSA co-localization is practically absent. Seventy-two hours after MPTP treatment, an activated phenotype is recognizable, with increased cell size. Labeling with MMP-9 (green) denotes some punctiform colocalization (arrows and enlarged boxed area). Nuclei are counterstained with DAPI (blue). Scale bars $20 \mu \mathrm{m}$; enlarged boxed area, $25 \mu \mathrm{m}$. $\mathbf{a}^{\prime}$ Quantitative analysis shows that a very few of the MMP-9 ${ }^{+}$ cells (black bars) are also GSA ${ }^{+}$(white bars), in both control (Cntr) and MPTP-treated mice. However, while the number of MMP-9 ${ }^{+}$ cells significantly decreases with respect to Cntr after MPTP injection, that of $\mathrm{GSA}^{+}$( gray bars) and of GSA ${ }^{+} / \mathrm{MMP}^{-} 9^{+}$microglial cells increases by 24 and $48 \mathrm{~h}$, respectively. These values decrease significantly, with respect to the $72 \mathrm{~h}$ time point, after 2 weeks. b Representative confocal images of double-immunolabeling of MMP-9 (green) and GFAP (red) in the SNpc of both control and MPTP-treated animals. As for microglia, in control animals, astrocytes are little and dispersed (arrowheads). Seventy-two hours after MPTP treatment, a prominent astrogliosis is evident, with increase in cell size, number and length of cell processes. MMP-9 and GFAP colocalized in part (arrows and enlarged boxed area). Nuclei are counterstained with DAPI (blue). Scale bars $20 \mu \mathrm{m}$; enlarged boxed area, $25 \mu \mathrm{m}$. $\mathbf{b}^{\prime}$ Quantitative analysis of $\mathrm{GFAP}^{+}$(gray bars) and $\mathrm{GFAP}^{+} / \mathrm{MMP}^{-}{ }^{+}$cells (white bars) show a significant increase in the number of labeled cells by $24 \mathrm{~h}$ after MPTP treatment with respect to Cntr. Both values decrease significantly at the end of the postoperative time considered, when the $\mathrm{GFAP}^{+}$cell number returns similar to Cntr. Quantitative analysis of $\mathrm{MMP}^{-}{ }^{+}$cells alone (black bars) or in co-localization with GSA (white bars in c) and GFAP (white bars in d) in the striatum. MMP- $9^{+}$cells increase significantly, with respect to control, after MPTP treatment, remaining high up to the 2 weeks time point. Also the number of both microglia $\left(\mathrm{GSA}^{+}\right.$ cells, gray bars in c) and astrocytes $\left(\mathrm{GFAP}^{+}\right.$cells, gray bars in d), increases. After 2 weeks, $\mathrm{GSA}^{+}$cells and $\mathrm{GFAP}^{+} / \mathrm{MMP}^{+} 9^{+}$cells decrease significantly with respect to the previous time point, while the number of $\mathrm{GSA}^{+} / \mathrm{MMP}_{-} 9^{+}$and $\mathrm{GFAP}^{+}$cells remains similar. For all quantitative analyses, $n=4$ animals/experimental group. Data are represented as the mean $\pm \mathrm{SEM}$ of the cell number $/ \mathrm{mm}^{2}$. $* p \leq 0.05$ (MPTP vs. Cntr), ${ }^{\wedge} p \leq 0.05$ ( 2 weeks vs. $72 \mathrm{~h} \mathrm{MPTP)} \mathrm{calculated} \mathrm{by}$ one-way ANOVA and Duncan's test

with respect to control (Fig. $7 b^{\prime}$ ). For the same technical reasons described for mice, we were unable to combine MMP-9 staining with classical markers of microglial cells.

Evaluation of nigro-striatal pathway degeneration and progression of neuroinflammation in MMP-9 KO and wild-type mice

Based on the results obtained so far, the main question remaining was related to whether MMP-9 could play a primary role in MPTP-induced neuroinflammation and, as a consequence, on SNpc DA neuron death. To unravel this question, we acutely treated MMP-9 KO mice and their matching WT with MPTP. Animals were killed $72 \mathrm{~h}$ and 2 weeks after MPTP administration, chosen as the most representative dates in the neuroinflammatory response of the nigro-striatal pathway. We performed HRP-DAB immunohistochemistry for: (a) $\mathrm{TH}$, to quantify DA neuron death in the $\mathrm{SN} p c$ and the decrease in DA innervation in the striatum; (b) Iba-1, to evaluate number and size of microglia; (c) GFAP, to evaluate number and size of astrocytes.

\section{Quantification of TH-immunoreactivity in the SNpc and striatum of wild-type and MMP-9 KO mice after MPTP treatment}

In both WT and MMP-9 KO mice, TH immunolabeling in the SN revealed the characteristic distribution of DA neurons in the pars compacta (Fig. 8a). However, the number of DA neurons $\left(\mathrm{TH}^{+}\right)$in untreated MMP-9 KO mice, was lower than in the WT, although this difference was not significant $(p=0.18)$. Due to this initial difference, to clearly evaluate changes in DA neuron number after MPTP treatment, we expressed this value as the percentage compared to control. MPTP treatment elicited significant loss of $\mathrm{TH}^{+}$neurons in the $\mathrm{SNpc}$ of both genotypes $72 \mathrm{~h}$ after the last MPTP injection (Fig. 8a, b, quantitative analysis). However, in MMP-9 KO mice, this reduction was significantly lower with respect to control, with $54 \%$ of $\mathrm{TH}^{+}$neurons left in the wild-type mice versus $82 \%$ in MMP-9 KO mice (Fig. 8b). As expected, 2 weeks after MPTP treatment, the percentage of $\mathrm{TH}^{+}$neurons increased in both genotypes (Fig. 8a, b, quantitative analysis), being in MMP-9 KO mice not significantly different than in the control mice (Fig. 8b). To further investigate this point, midbrain sections of control and MPTP-treated mice were stained with cresyl violet and the total number of neurons counted. The graph in Fig. 8c shows a significant neuronal loss $72 \mathrm{~h}$ after MPTP injection, which does not recover after 2 weeks. Moreover, the number of neurons in MPTP-treated KO mice is always significantly higher than that in the WT. This result definitely demonstrates that, after MPTP treatment, not all $\mathrm{SN} p c$ neurons die, but a number of affected neurons just stop synthesizing and transporting $\mathrm{TH}$ along the axons, being able to recover from toxic treatment.

In the striatum, TH immunolabeling (evaluated as OD of gray scale units) was lower, although not significantly $(p=0.44)$, in MMP-9 KO mice with respect to WT (Fig. 8d, e, densitometric analysis), reasonably due to the presence of a fewer number of DA neurons in the $\mathrm{SN} p c$ of control mice. MPTP administration elicited a significant decrease (72 h) and successive recovery ( 2 weeks vs. $72 \mathrm{~h}$ ) in TH immunolabeling, although values remained lower than controls (Fig. 8d, e, densitometric analysis). Different from the $\mathrm{SN} p c$, no significant differences were 
Fig. 6 Pie charts resuming the changes in the number of the different cell types expressing MMP-9 in the mouse $\mathrm{SN} p c$ and striatum. MMP-9 is mainly expressed by neurons in both $\mathrm{SNpc}$ (left column) and striatum (right column). The percentage of MMP- $9^{+}$neurons decreases significantly after MPTP treatment, in coincidence with dopaminergic neuron loss and neuroinflammation (24-72 h), whereas that of MMP- $9^{+}$ microglia, astrocytes and other types of cells increases. Two weeks after MPTP treatment, percentages return similar to control
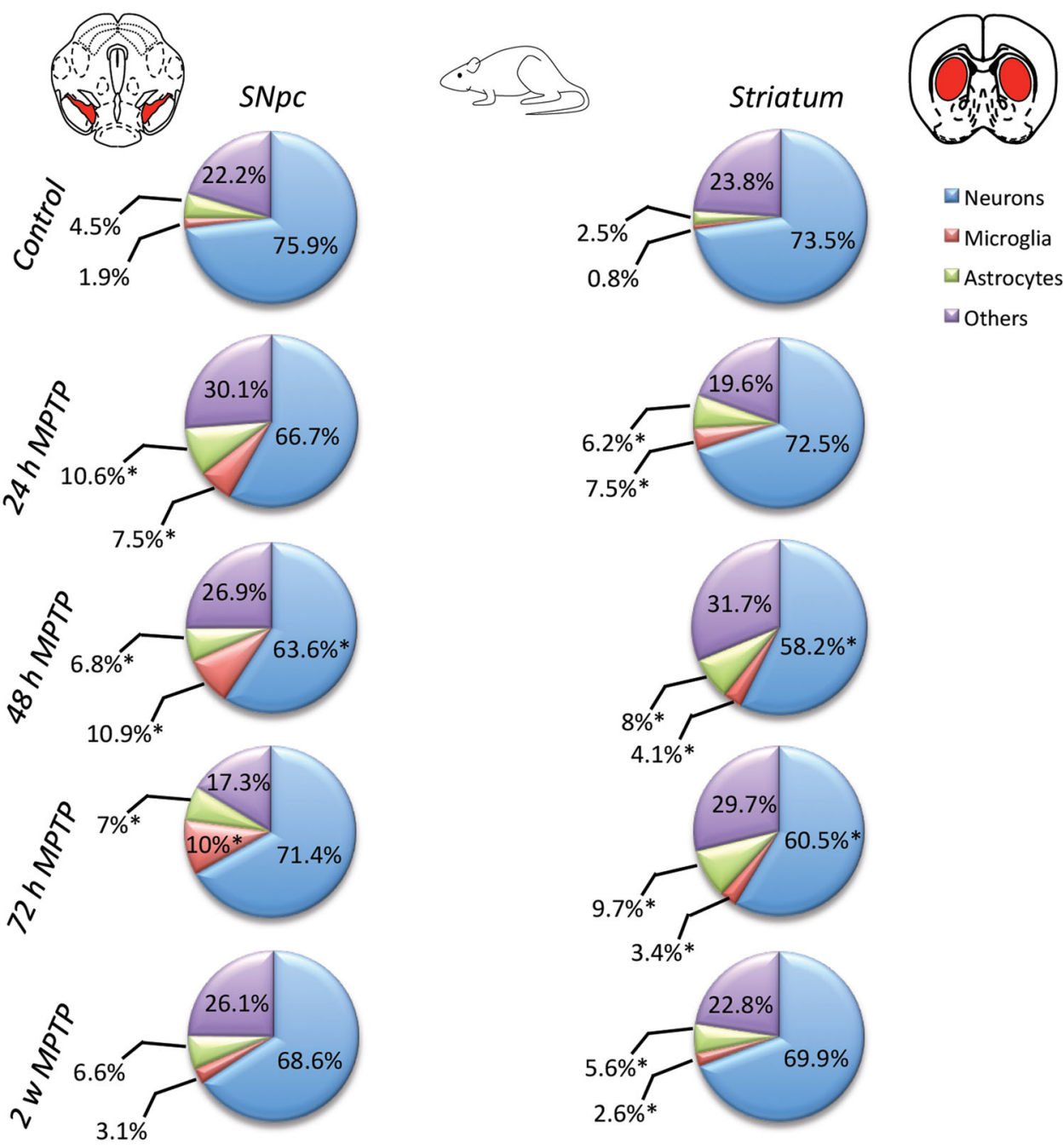

$\square$ Neurons

$\square$ Microglia

$\square$ Astrocytes

$\square$ Others
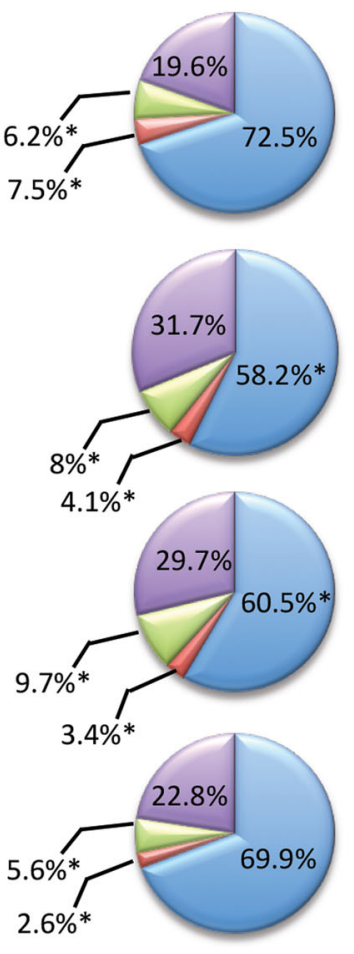

observed in the striatum between WT and MMP-9 KO mice at both $72 \mathrm{~h}$ and 2 weeks after MPTP treatment, although the recovery of $\mathrm{TH}$ immunolabeling in the $\mathrm{KO}$ mice was more significant $(p<0.05$, when evaluated by the Student's $t$ test) than in the WT. Once more, these data suggest that lack of MMP-9 protects DA neurons from death, reflected also in a higher degree of striatal DA reinnervation.

\section{Quantification of Iba-1-immunopositive $\left(I b a-I^{+}\right)$cells in the SNpc and striatum of wild-type and MMP-9 KO mice after MPTP treatment}

We performed immunolabeling on brain sections, adjacent to those immunoreacted for $\mathrm{TH}$, with an antibody directed against Iba-1, a microglia cell-specific protein, which labels both resting and active microglia. Figure 9a shows Iba-1 immunoreactivity in the SN of control and MPTPtreated mice. Differences in the overall intensity of immunolabeling between experimental groups can be appreciated, as well as the appearance of large and intensely

Fig. 7 MMP-9 expression in neurons and astrocytes significantly increases in the caudate and putamen of parkinsonian Macaca fascicularis, coinciding with a chronic and massive neuroinflammation. Confocal study of MMP-9 co-immunolabeling with NeuN and GFAP in the caudate and putamen of control and MPTP-treated monkeys and relative quantitative analyses. a MMP-9 immunofluorescence (green) decorates the cell bodies of numerous cells, mainly with a glial morphology. Co-localization of MMP-9 and NeuN (purple) (arrows and enlarged boxed areas) increases after 2 years of stable Parkinsonism. Nuclei are counterstained with DAPI (blue). Scale bars $25 \mu \mathrm{m}$. $\mathbf{a}^{\prime}$ Quantitative analysis of MMP-9 $9^{+}$(black bars), $\mathrm{NeuN}^{+}$(gray bars) and $\mathrm{NeuN}^{+} / \mathrm{MMP}_{-} 9^{+}$(white bars) cells indicates a significant increase, with respect to control (Cntr), in the number of cells expressing MMP-9, including neurons, after induction of stable parkinsonism in both caudate and putamen. Differently, the number of striatal neurons remains unchanged. b Co-immunolabeling of MMP-9 (green) and GFAP (red) shows a clear astrogliosis after MPTP treatment. A number of cells and processes are immunolabeled with both markers (arrows and enlarged boxed areas). Nuclei are stained with DAPI (blue). Scale bars $25 \mu \mathrm{m}$. $\mathbf{b}^{\prime}$ Quantitative analysis of MMP-9 ${ }^{+}$(black bars), GFAP ${ }^{+}$(gray bars) and GFAP ${ }^{+} / \mathrm{MMP}^{-}{ }^{+}$ (white bars) cells show a significant increase, with respect to control, in the number of astrocytes, expressing or not MMP-9, in both caudate and putamen. $n=3$ monkeys (control) and 5 monkeys (Parkinsonian). For all quantitative analyses, data are represented as the mean \pm SEM of cell number $/ \mathrm{mm}^{2}$. $* p \leq 0.05$, ** $*^{*} \leq 0.01$, *** $p \leq 0.001$ calculated by the Student's $t$ test 

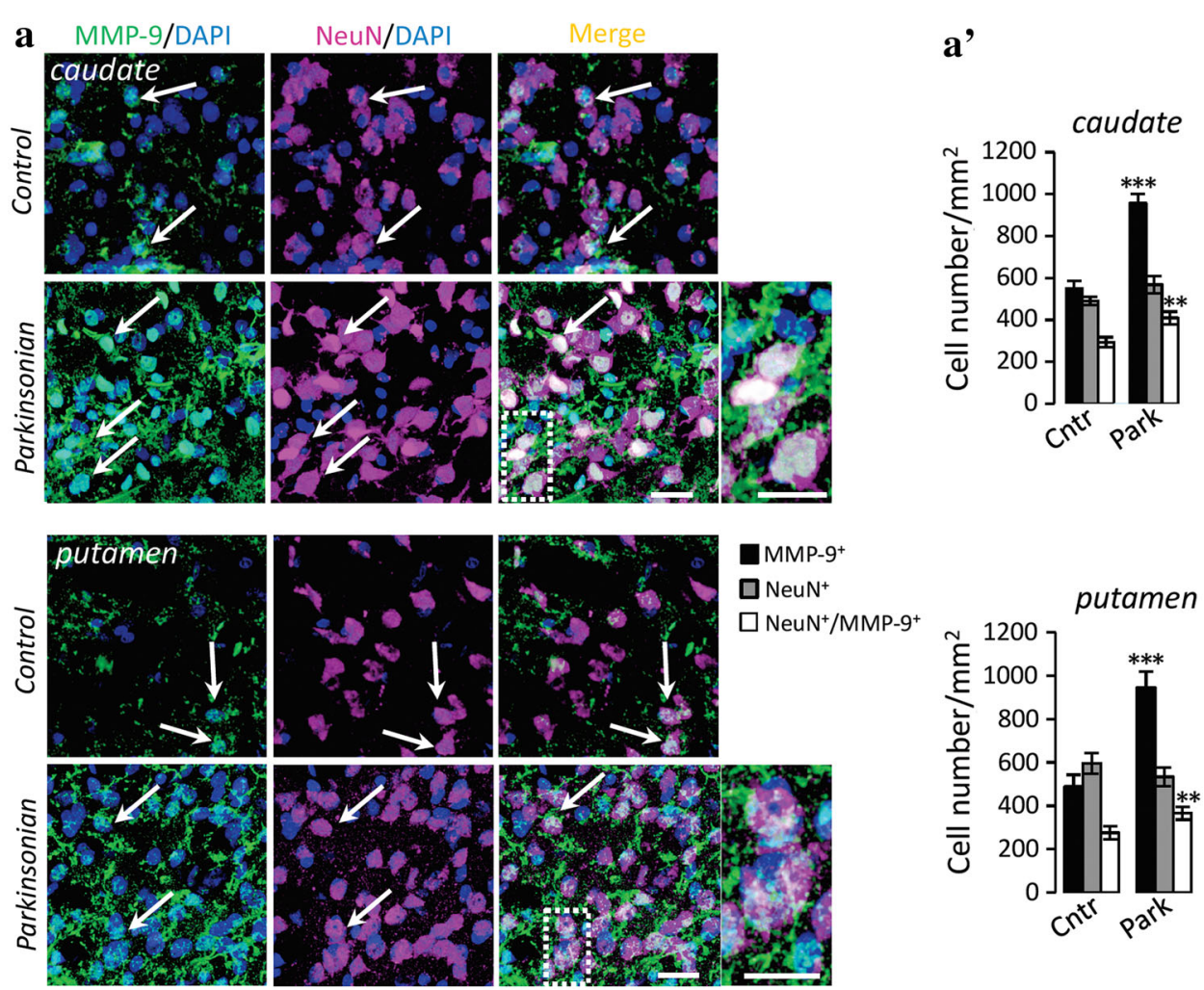

$\square \mathrm{NeuN}^{+}$

$\square \mathrm{NeuN}^{+} / \mathrm{MMP}^{-9+}$
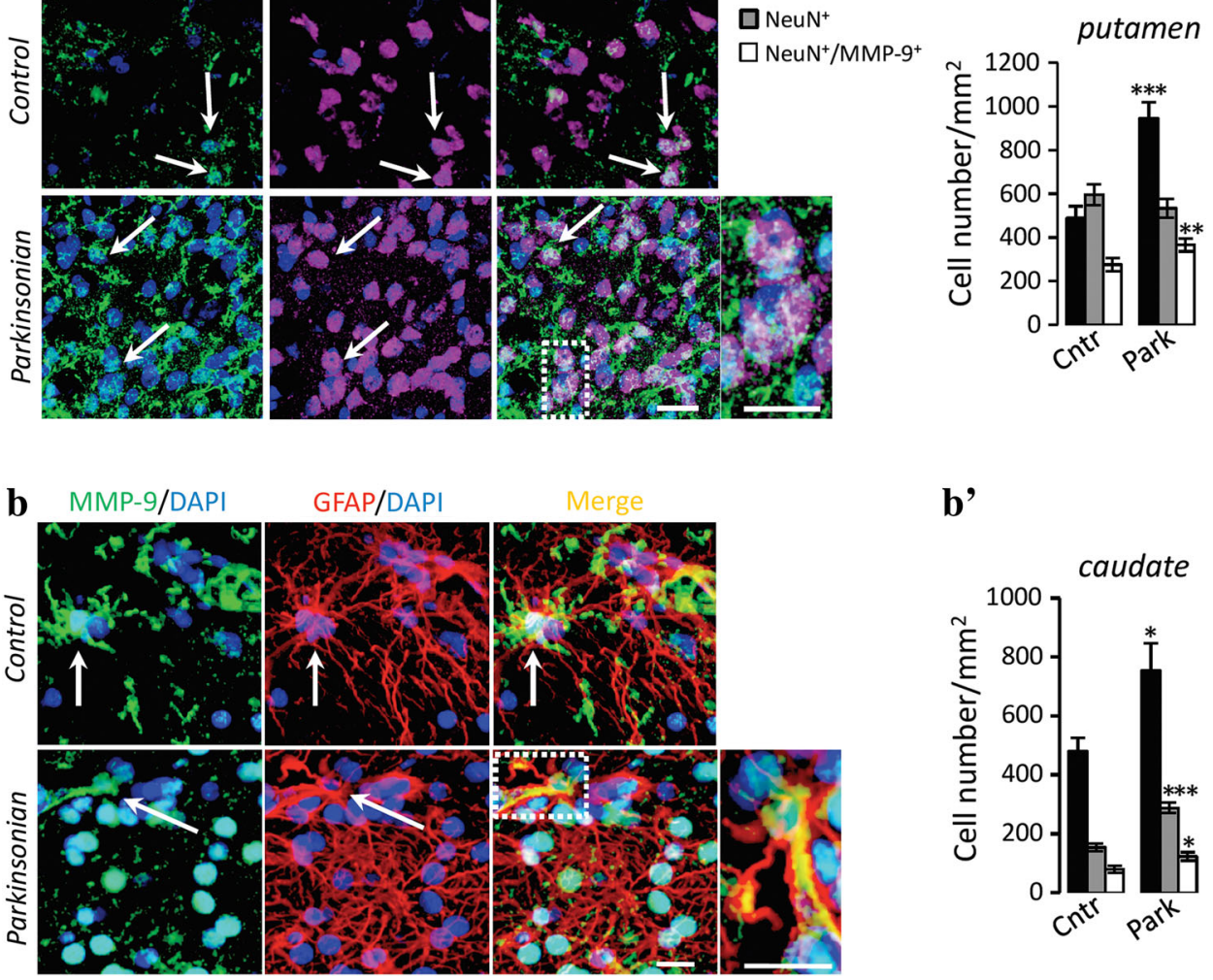

b'
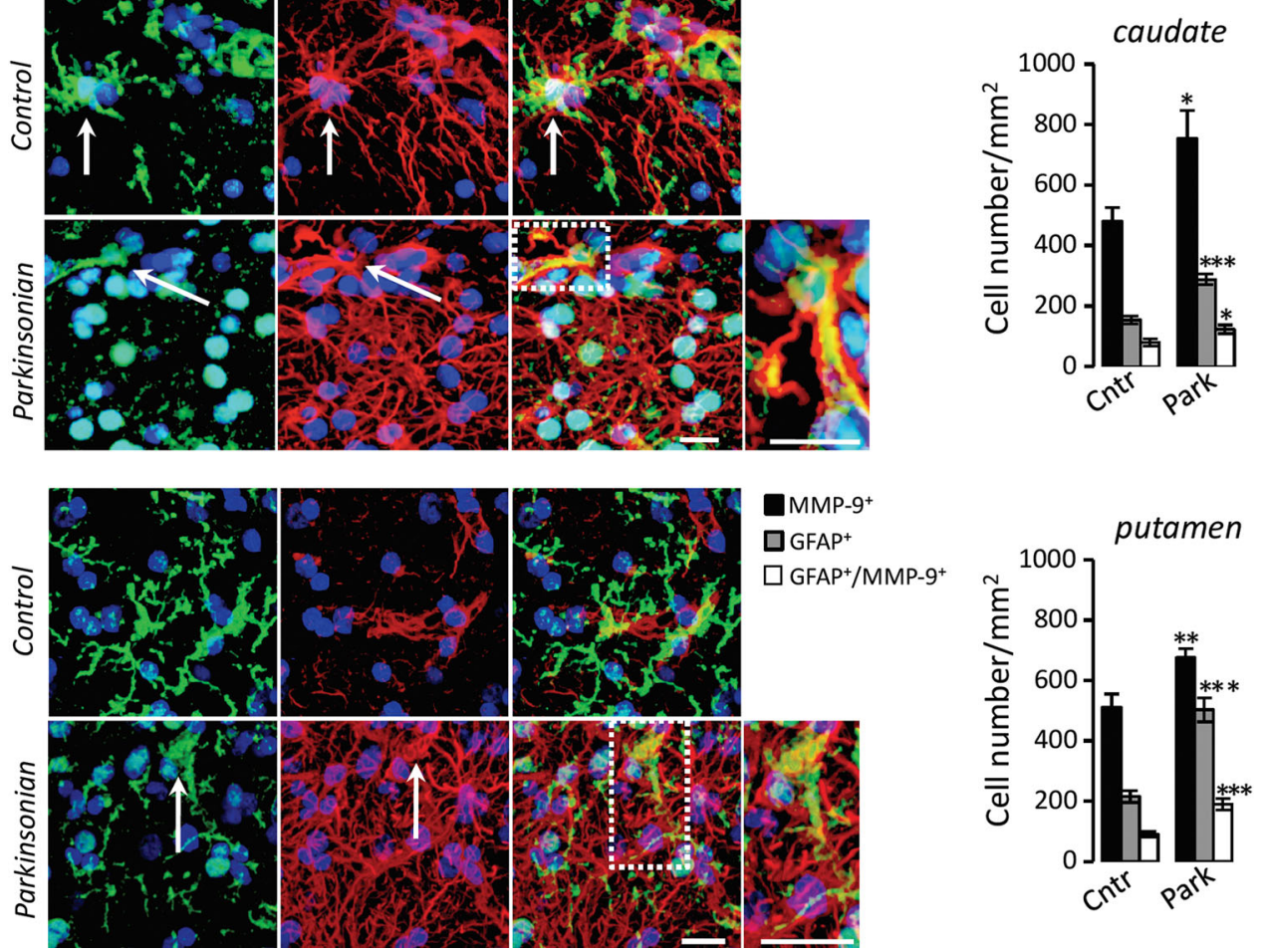

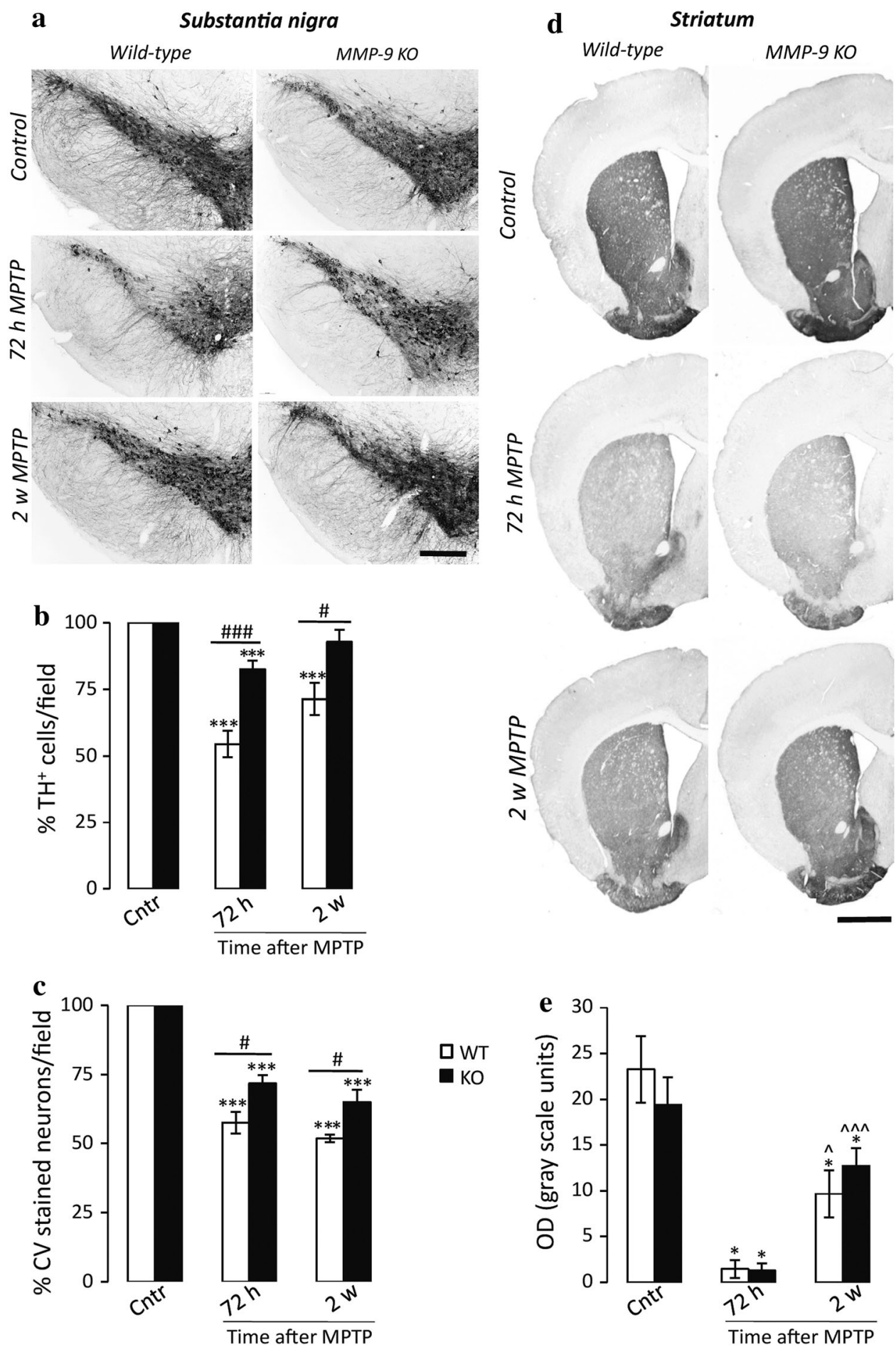

labeled Iba- $1^{+}$cells $72 \mathrm{~h}$ after MPTP treatment in both WT and MMP-9 KO mice. Details of microglial cells in WT (Fig. 9a ${ }^{1}$, control; Fig. 9a ${ }^{2}, 72$ h MPTP) and MMP-9-KO (Fig. $9 \mathrm{a}^{3}$, control; Fig. $9 \mathrm{a}^{4}, 72$ h MPTP) mice clearly show an increase in cell size and in the amount of processes after MPTP treatment with respect to untreated controls, in both genotypes. However, changes in WT mice are more pronounced than in MMP-9 KO mice. These differences were confirmed by quantitative analysis, in which we evaluated mean cell number/area, mean area/cell and total area occupied by all Iba1 ${ }^{+}$cells. The number of microglial cells increased significantly $72 \mathrm{~h}$ after MPTP treatment, and 
4Fig. 8 After MPTP treatment, the amount of dopaminergic neurons and fibers in the substantia nigra pars compacta ( $\mathrm{SNpc}$ ) and striatum is significantly higher in MMP-9 KO mice with respect to wild-type. a $\mathrm{TH}$ immunohistochemistry in the $\mathrm{SN} p c$ of both wild-type and MMP-9 KO mice shows a decrease $(72 \mathrm{~h})$ of the immunolabeling after MPTP treatment with respect to control. This reduction partially recovers after 2 weeks from the treatment. Scale bar $400 \mu \mathrm{m}$. b Quantitative analysis of the number of $\mathrm{TH}^{+}$cells (expressed as the percentage with respect to their own control) confirms this pattern and shows that the number of dopaminergic neurons expressing $\mathrm{TH}$ is always significantly higher in the KO genotype (black bars) with respect to wild-type (white bars). Partial, but significant, retrieval of $\mathrm{TH}^{+}$neurons at the 2 weeks time point indicates that a number of dopaminergic neurons survive MPTP intoxication and recover their functionality. c Quantitative analysis of the changes of SNpc neurons, stained with the histological dye cresyl violet, was performed to ascertain neuronal loss with respect to TH-expressing neurons. Data demonstrate effective and definitive loss of a percentage of neurons after MPTP treatment in both genotypes (without recovery after 2 weeks). The number of lost neurons was always significantly higher in wild-type mice (white bars) with respect to MMP-9 KO (black bars). d As for the $\mathrm{SNp} p$, $\mathrm{TH}$ immunostaining of striatal sections shows an evident decrease $(72 \mathrm{~h})$ and successive partial recovery ( 2 weeks) of immunolabeling after MPTP treatment with respect to control, in both wild-type and MMP-9 KO mice. Scale bar $1 \mathrm{~mm}$. e Densitometric analysis of the immunopositive signal confirms a significant drastic decrease in TH immunolabeling $72 \mathrm{~h}$ after MPTP treatment and a significant recovery after 2 weeks. $n=5$ mice (wildtype) and 8 mice (MMP-9 KO). For all quantitative analyses, data are represented as the mean \pm SEM of the number of neurons $(\mathbf{b}, \mathbf{c})$ and of the OD in MPTP-treated mice/control (e). $* p \leq 0.05$, $* * * p \leq 0.001$ (MPTP vs. Cntr), ${ }^{\#} p \leq 0.05,{ }^{\# \# p} p \leq 0.001$ (MMP-9 $\mathrm{KO}$ vs. wild-type mice), ${ }^{\wedge} p \leq 0.05,{ }^{\wedge \wedge} p \leq 0.001$ (2 weeks vs. $72 \mathrm{~h}$ MPTP), calculated by the Student's $t$ test

began to decline by 2 weeks compared to the $72 \mathrm{~h}$ time point, although remaining higher than control (Fig. 9b). We did not observe differences in cell numbers between the two genotypes, in both control and MPTP-treated mice, meaning that the absence of MMP-9 does not affect microglia cell generation, division and recruitment to the site of damage. Both mean cell area (Fig. 9c) and total area/field occupied by $\mathrm{Iba}^{+}$cells (not shown) changed according to cell number. However, $72 \mathrm{~h}$ after treatment, when microglia activation is at its maximum, these values were significantly lower in MMP-9 KO mice with respect to WT mice.

In the striatum, results were comparable to those in the SNpc. Figure 9d is representative of Iba- 1 immunolabeling in the different experimental groups. Insets into the figures highlight the morphological characteristics of individual cells, in which differences in cell size between WT and MMP-9 KO mice after MPTP treatment can be appreciated. Statistical analyses relative to $\mathrm{Iba}^{-} 1^{+}$cell number (Fig. 9e), mean cell area (Fig. 9f), and total area/field occupied by $\mathrm{Iba}^{+}$cells (not shown) are in accordance with the statistics in the SNpc. As a notable exception, 2 weeks after MPTP treatment, mean cell size remains higher in WT animals compared to untreated controls, suggesting a prolongation of the inflammatory reaction with respect to what happens in the SN.

Quantification of GFAP-immunopositive $\left(G F A P^{+}\right)$cells in the SNpc and striatum of wild-type and MMP-9 KO mice after MPTP treatment

Figure 10a shows GFAP immunolabeling in sections of the SN from control and MPTP-treated WT and MMP-9 KO mice. Intensity and distribution of the immunostaining increased $72 \mathrm{~h}$ after MPTP injection with respect to control, decreasing again after 2 weeks. Astrocyte morphological changes after MPTP treatment in WT (Fig. 10a ${ }^{1}$, control; Fig. $10 \mathrm{a}^{2}, \quad 72 \mathrm{~h}$ MPTP) and MMP-9-KO (Fig. 10a ${ }^{3}$, control; Fig. 10a ${ }^{4}, 72 \mathrm{~h}$ MPTP) mice are shown. Quantitative analysis of the changes in $\mathrm{GFAP}^{+}$cell number (Fig. 10b), mean cell size (Fig. 10c), and total area/photographic field occupied by $\mathrm{GFAP}^{+}$cells (not shown) was fairly similar to what was previously described for microglia: i.e. all parameters increased $72 \mathrm{~h}$ after MPTP treatment and began to decline within 2 weeks. Similar to microglia, $72 \mathrm{~h}$ after MPTP administration, the absence of active MMP-9 did not produce differences between the two genotypes in terms of astrocyte cell numbers (Fig. 10b), but only in cell size (Fig. 10c).

In the striatum, results were comparable to those in the $\mathrm{SN} p c$. Figure 10d shows GFAP immunolabeling in control WT and MMP-9 KO mice and the changes after MPTP treatment (details of single astrocytes for each experimental group are shown in the inset of figures). Quantitative analyses are reported in Fig. 10e $\left(\mathrm{GFAP}^{+}\right.$cell number) and Fig. 10f (mean cell area).

Data collected from the experiments on WT and MMP-9 KO mice were compared to each other in a correlation study. A significant inverse correlation between cell number and size (mean and total area) of both $\mathrm{Iba}^{+} 1^{+}$and $\mathrm{GFAP}^{+}$cells and a decrease in $\mathrm{TH}^{+}$cell number and $\mathrm{TH}^{+}$ fibers in the $\mathrm{SN} p c$ and striatum, respectively, were observed (Fig. 11).

\section{Discussion}

Neuroinflammation is a feature of PD common to several brain pathologies. Its cellular and molecular aspects have, therefore, become a major field of investigation as a unifying ground on the causative and/or aggravating element of neurodegenerative diseases. Animal models of Parkinsonism, as those adopted in this study, allow the identification of the temporal and cellular basis of neuroinflammation, its correlation with the primary degeneration of DA nigro-striatal pathway and the molecular signals involved. 


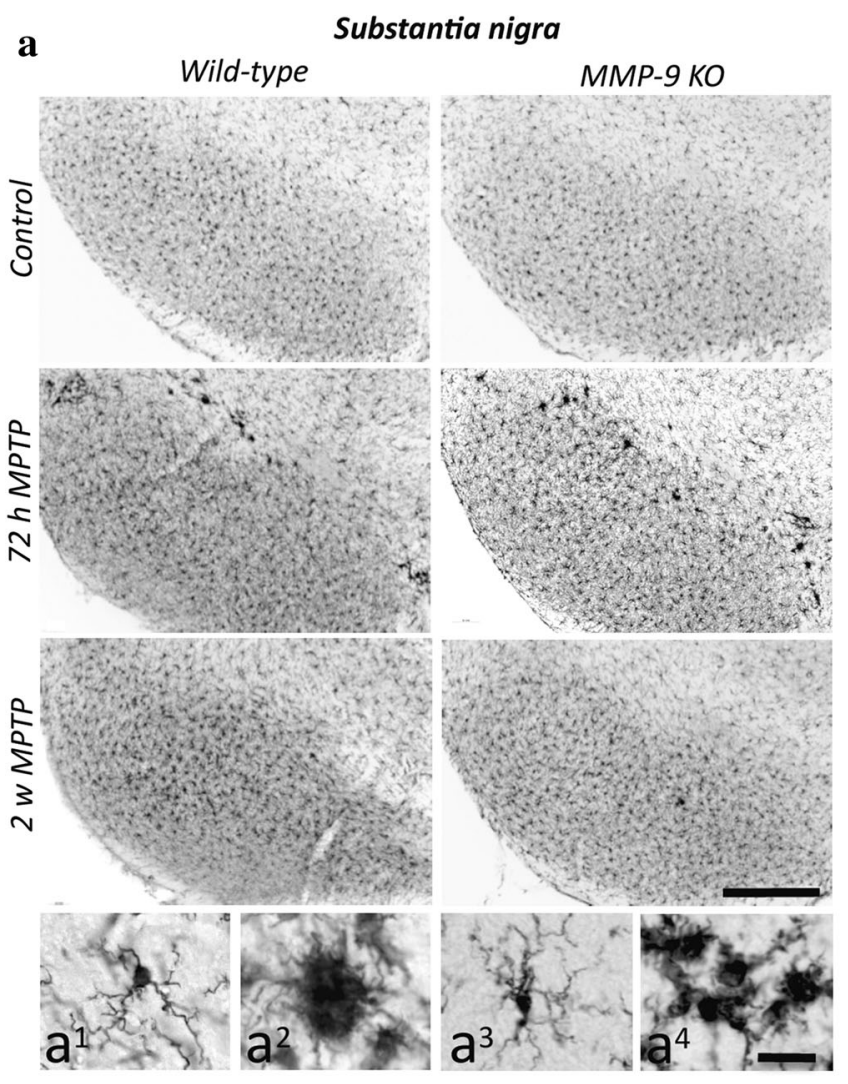

b
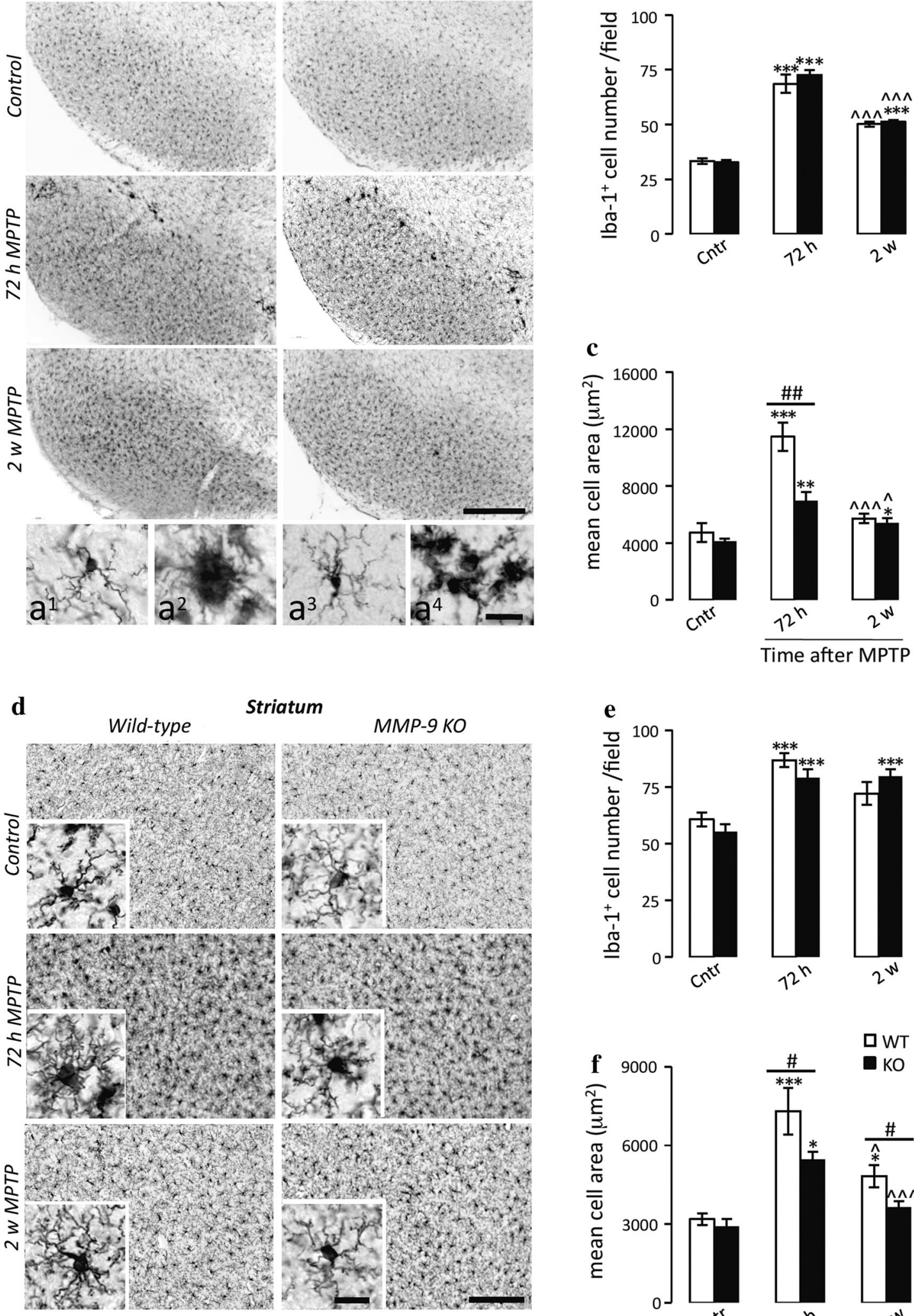

e

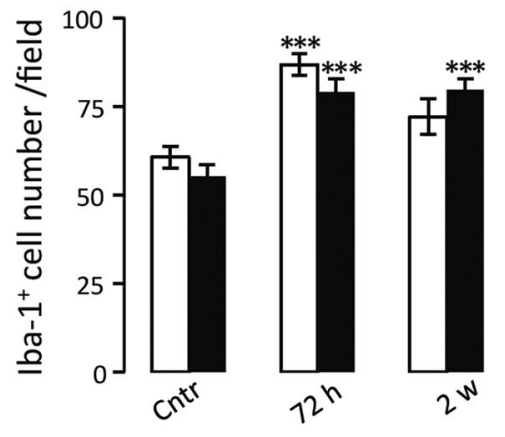

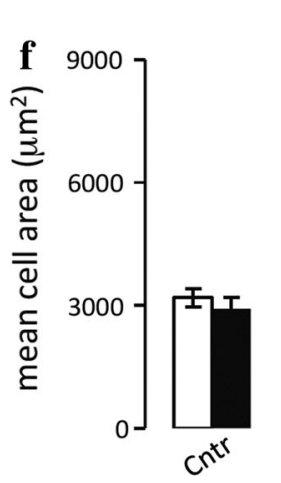

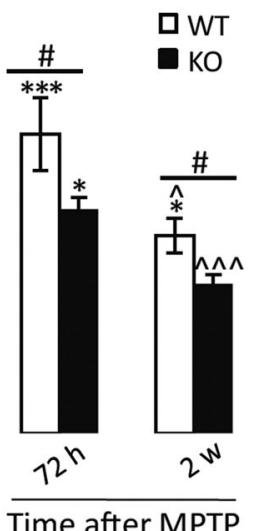


4Fig. 9 MPTP treatment induces a prominent microgliosis in the substantia nigra pars compacta $(\mathrm{SN} p c)$ and striatum of both wild-type and MMP-9 KO mice, but the mean cell size is significantly reduced in the KO genotype. a, d Iba-1 immunohistochemistry in the SNpc (a) and striatum (d) of both wild-type and MMP-9 KO mice shows an increase, with respect to control, in the amount of clusters of reactive microglia $72 \mathrm{~h}$ after MPTP treatment. After 2 weeks, number and size of microglial cells begin to reduce with respect to the $72 \mathrm{~h}$ postinjection time. Insets show details of microglia morphology, before and after MPTP treatment. Insets in panel $\mathbf{a}(\mathrm{SN} p c)$ : $\mathbf{a}^{\mathbf{1}}, \mathbf{a}^{\mathbf{3}}$ are enlargements of microglial cells in control wild-type and MMP-9 KO mice, respectively; $\mathbf{a}^{\mathbf{2}}, \mathbf{a}^{\mathbf{4}}$ are enlargements of microglial cells $72 \mathrm{~h}$ after MPTP treatment of wild-type and MMP-9 KO mice, respectively. Scale bars a, $400 \mu \mathrm{m}$; d, $200 \mu \mathrm{m}$; insets $20 \mu \mathrm{m}$. b, e Quantitative analysis on Iba- $1^{+}$cells in the SNpc and striatum of wild-type and MMP-9 KO mice shows that the number of microglial cells increases significantly $72 \mathrm{~h}$ after MPTP treatment and begins to decrease after 2 weeks, although remaining higher than control (Cntr). No differences are observed between the two genotypes. Data are represented as the mean \pm SEM of the cell number/photographic field. c, f Quantitative analysis on $\mathrm{Iba}_{-}{ }^{+}$cells in the $\mathrm{SN} p c$ and striatum of wild-type and MMP-9 KO mice shows that the mean area occupied by each microglial cell significantly increases $72 \mathrm{~h}$ after MPTP treatment, with respect to $\mathrm{Cntr}$, and then decreases after 2 weeks. However, in MMP-9 KO mice, this parameter is significantly lower compared to wild-type, at least after $72 \mathrm{~h}$. $n=5$ mice (wild-type) and 8 mice (MMP-9 KO). For all quantitative analyses, data are represented as the mean \pm SEM of cell area $\left(\mu \mathrm{m}^{2}\right)$; ${ }^{*} p \leq 0.05,{ }^{*} p \leq 0.01, * * * p \leq 0.001$ (MPTP vs. Ctrl); ${ }^{\wedge} p \leq 0.05$, ${ }^{\wedge \wedge \wedge} p \leq 0.001$ (2 weeks vs. $\left.72 \mathrm{~h} \mathrm{MPTP}\right) ;{ }^{\# p} \leq 0.05$, ${ }^{\# \#} p \leq 0.01$ (MMP-9 KO vs. wild-type), calculated by the Student's $t$ test

After MPTP intoxication, microglia is early recruited, followed by $\mathrm{T}$-cell infiltration and astrogliosis when neuronal loss has already progressed (Hirsch and Hunot 2009). Perpetuation of microgliosis can, therefore, be a crucial non-turning point for neuron degeneration. After a harmful event, reactive microglia is involved in scavenging neuronal debris; however, an adverse role emerges when proinflammatory cytokines (i.e. INT- $\gamma$; TNF- $\alpha$ ) perpetuate inflammation, favoring neurodegeneration (Barcia et al. 2005, 2011; Pott Godoy et al. 2008). In this study, MPTPtreated mice develop a prominent but transient inflammation, which coincides with DA neuron and fiber degeneration; successive remission of this inflammation correlates with functional recovery of surviving neurons. By combining TH immunohistochemistry and cresyl violet staining, we confirmed that part of the DA neurons in the lesioned SNpc may be only temporarily affected, remaining functionally silent for a short time and with great potentiality to survive intoxication and to partially reinnervate the striatum, as previously reported in both MPTPtreated mice and monkeys (Bezard et al. 2000; Mounayar et al. 2007). Although the observations in mice are different than the irreversible degeneration that MPTP provokes in humans (Langston et al. 1983) and monkeys (Barcia et al. 2004), these results pose a new ground for studies aimed at uncovering molecular mechanisms promoting rescue of affected neurons and re-establishing nigro-striatal connections.

The major point of this study was to identify factors responsible for the perpetuation of glia proliferation and/or activation, which shifts a beneficial response, intended to maintain brain homeostasis, into a deadly chronic state. A role could be played by MMPs, involved in several CNS injuries and diseases, but at the same time promoters of neuro-reparative and physiological processes (Yong 2005; Zhang et al. 2010; De Stefano et al. 2012). MMPs detrimental role relies on the unbalance of the delicate equilibrium between activation and inhibition; therefore, reestablishment of this equilibrium could be a therapeutic strategy aimed at modulating neuroinflammation.

Related to Parkinsonism, in vitro studies have demonstrated intracellular activation of MMP-3 after neuronal stress, with consequent induction of apoptotic-signaling cascades (Choi et al. 2008; Kim et al. 2010). MMP-3 released by dying neurons activates microglia, further contributing to neurodegeneration (Kim et al. 2007) along with MMP-9 (Woo et al. 2008). Altered gelatinase expression in the SN of post-mortem brains of PD patients was first reported by Lorenzl et al. (2002), according to whom no alteration in MMP-9 protein and activity levels were observed compared to age-matched controls. Later on, the same authors reported an increase in MMP-9 mRNA, protein, and activity levels in the $\mathrm{SN}$ and striatum of pools of MPTP-treated mice (Lorenzl et al. 2004), although these data were not detailed in terms of postinjection times, and lacked a proper quantitative/qualitative evaluation of the type/s of cells in which MMP-9 expression was modulated. According to our data, MMP-9 indeed turns out to be highly expressed and modulated in mouse $\mathrm{SN} p c$ and striatum from the very first stages of MPTPinduced neuroinflammation, and throughout the 2 weeks period of observation. Qualitative and quantitative data, obtained by co-immunolabeling MMP-9 with different cell-specific markers, show significant enhancement of MMP-9 expression in reactive microglia and astrocytes recruited in $\mathrm{SNpc}$ and striatum. This is in accord to the literature, where it is reported that neurons, microglia and astrocytes synthesize both gelatinases (MMP-2 and MMP9), although MMP-9 is the only highly modulated under experimental conditions (Yong 2005; Wilczynski et al. 2008; Candelario-Jalil et al. 2009; Walker and Rosenberg 2010). In MPTP-injected mice, neuroinflammation is transient and starts decreasing within 2 weeks after the treatment, when the number of $\mathrm{MMP}-9^{+}$microglia and astrocytes in the nigro-striatal pathway declines to control levels. This overlaps the partial recovery of $\mathrm{TH}$ protein levels and $\mathrm{TH}^{+}$neurons and fibers (Annese et al. 2013; this study), suggesting that glial MMP-9 is a major player in the 


$$
\mathbf{a}
$$

$\mathbf{a}$

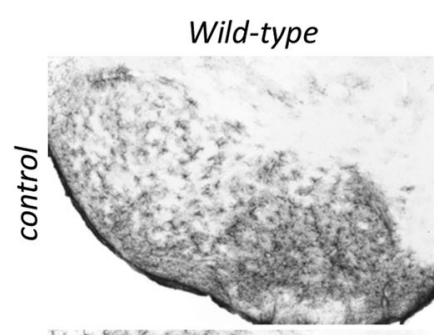

\section{Substantia nigra}

MMP-9 KO
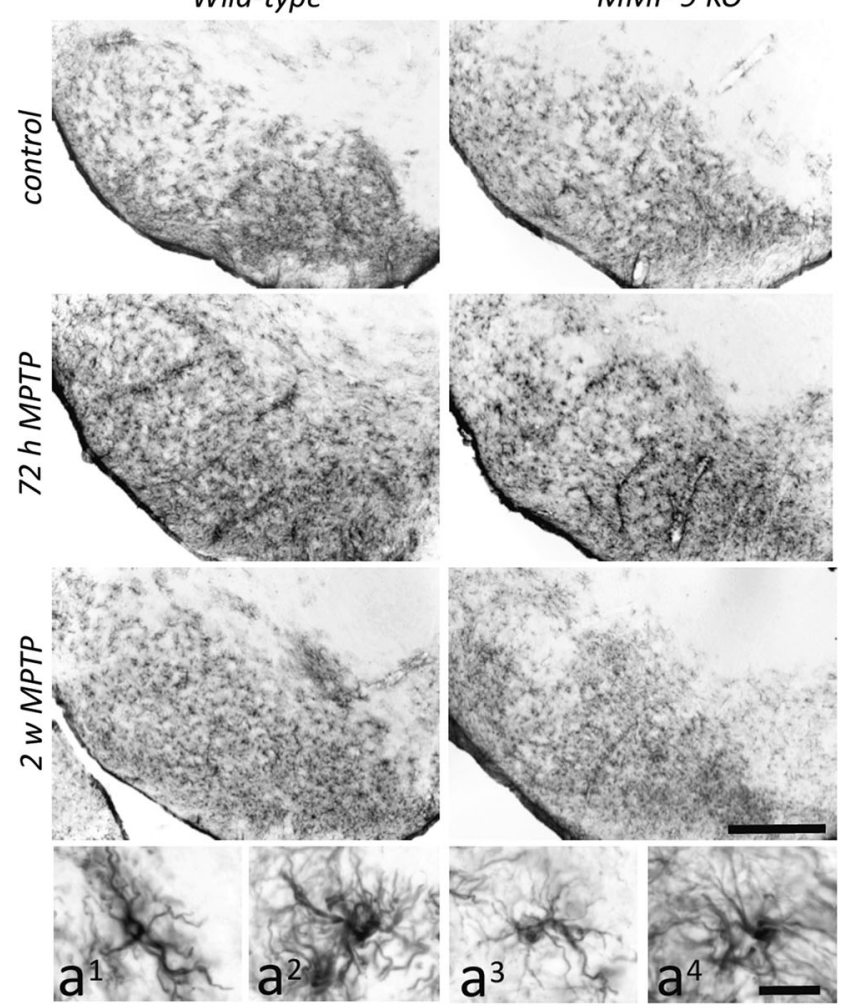

d

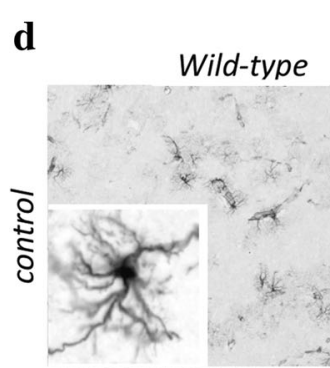

\section{Striatum}
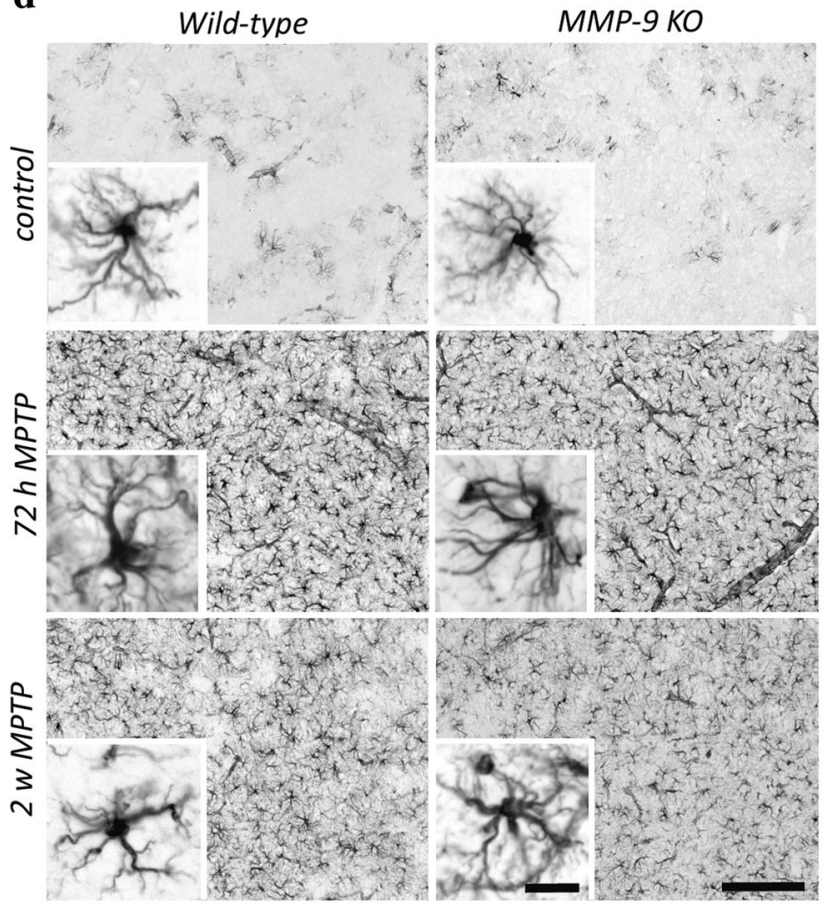

b
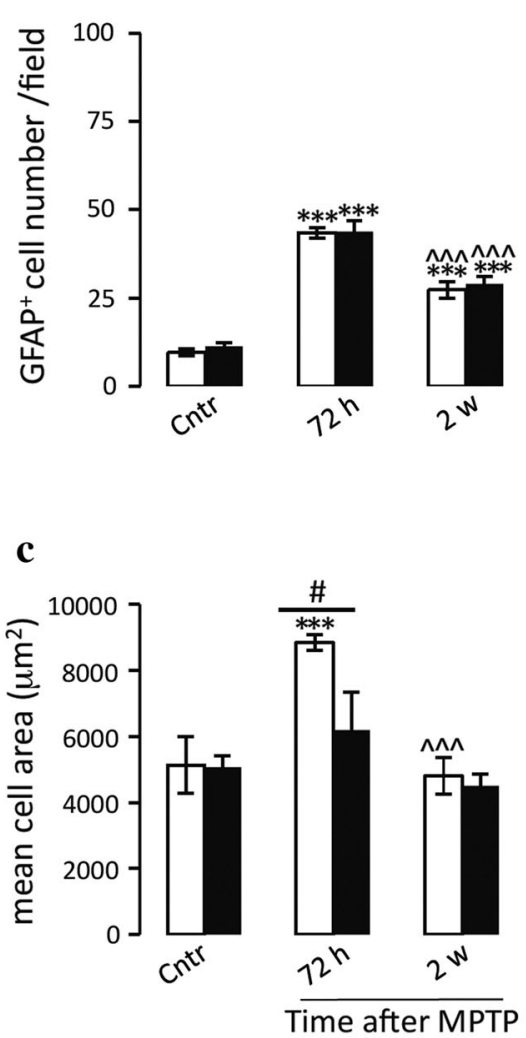

e
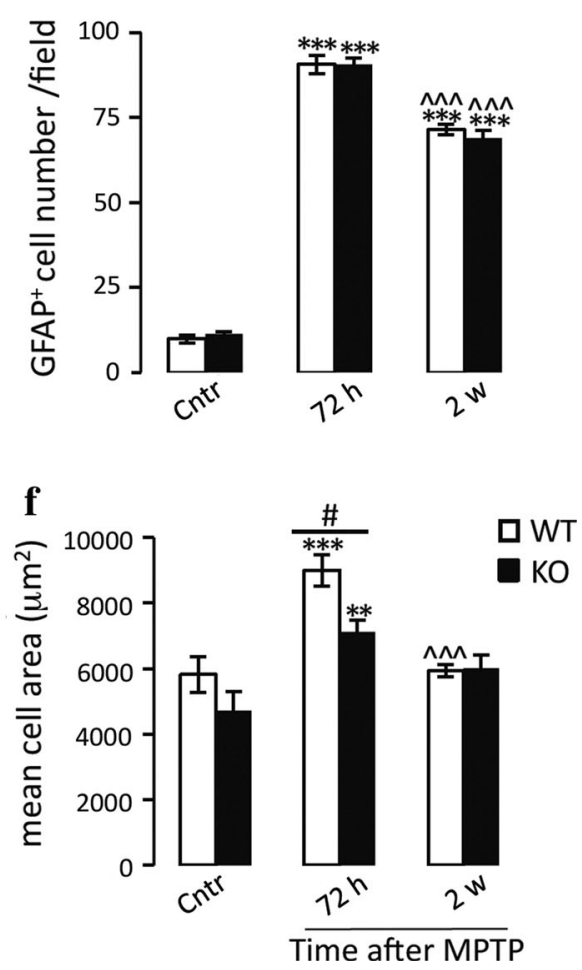
4Fig. 10 MPTP treatment induces a prominent astrogliosis in the substantia nigra pars compacta ( $\mathrm{SNpc}$ ) and striatum of both wild-type and MMP-9 KO mice, but the mean cell size is significantly reduced in the KO genotype. GFAP immunohistochemistry in the SNpc (a) and striatum (d) of both wild-type and MMP-9 KO mice shows an increase, with respect to control, in the amount of reactive astrocytes $72 \mathrm{~h}$ after MPTP treatment. Reactive astrocytes increase cell size and complexity of their processes. After 2 weeks, astrocyte number and size begin to reduce with respect to the $72 \mathrm{~h}$ post-injection time. Insets show details of astrocyte morphology, before and after MPTP treatment. Insets to panel $\mathbf{a}(\mathrm{SN} p c)$ : $\mathbf{a}^{\mathbf{1}}$ and $\mathbf{a}^{\mathbf{3}}$ are enlargements of astrocytes in control wild-type and MMP-9 KO mice, respectively; $\mathbf{a}^{2}$ and $\mathbf{a}^{\mathbf{4}}$ are enlargements of astrocytes $72 \mathrm{~h}$ after MPTP treatment of wild-type and MMP-9 KO mice, respectively. Scale bars a, $400 \mu \mathrm{m}$; d, $200 \mu \mathrm{m}$; insets, $20 \mu \mathrm{m}$. b, e Quantitative analysis on $\mathrm{GFAP}^{+}$cells in the SNpc and striatum of wild-type and MMP-9 KO mice shows that the number of astrocytes increases significantly $72 \mathrm{~h}$ after MPTP treatment and begin to decrease after 2 weeks, although remaining higher than control (Cntr). No differences are observed between the two genotypes. Data are represented as the mean $\pm \mathrm{SEM}$ of the cell number/photographic field. c, f Quantitative analysis on $\mathrm{GFAP}^{+}$cells in the SNpc and striatum of wild-type and MMP-9 KO mice shows that the mean area occupied by each astrocyte significantly increases $72 \mathrm{~h}$ after MPTP treatment, with respect to $\mathrm{Cntr}$, and then decreases after 2 weeks. However, $72 \mathrm{~h}$ after MPTP treatment, this parameter in MMP-9 KO mice is significantly lower compared to wild-type. $n=5$ mice (wild-type) and 8 mice (MMP-9 KO). For all quantitative analyses, data are represented as the mean \pm SEM of cell area $\left(\mu \mathrm{m}^{2}\right)$; $* * p \leq 0.01, * * * p \leq 0.001$ (MPTP vs. Ctrl); ${ }^{\wedge \wedge} \wedge p \leq 0.001$ (2 weeks vs. 72 h MPTP); ${ }^{p} p \leq 0.05$ (MMP-9 KO vs. wild-type), calculated by the Student's $t$ test

ignition of neuroinflammation. Specifically, based on the results obtained in KO mice, MMP-9 appears to be important for glia "activation", but not proliferation. In fact, $72 \mathrm{~h}$ after MPTP treatment, while the number of microglia and astrocytes in both SNpc and striatum of WT and MMP-9 KO mice are similar, mean cell size and the total area that reactive glia occupies per section are significantly higher in WT mice. This difference disappears after 2 weeks, when inflammation is subsiding. In the striatum, both the number of MMP- $9^{+}$glial cells and TH protein levels decline slower than in the $\mathrm{SN} p c$, possibly related to its complex circuitry. Striatal response to MPTP is prompt, as the toxin first affects SNpc neuron activity and viability (Herkenham et al. 1991), with consequent striatal neuronal denervation and retrograde reaction of cortical neurons, which also project to the striatum, exacerbating and prolonging the inflammatory process.

Data on MMP-9 KO mice indicate that inflammatory glia hampers neuron survival, as a reduction in reactive glia with respect to WT correlates with a higher number of $\mathrm{TH}^{+}$ neurons (functional DA neurons) and cresyl violet-stained neurons (effective number of neurons) in the $\mathrm{SN} p c$, at both $72 \mathrm{~h}$ and 2 weeks post-treatment. We do not exclude that MMP-9, early released by affected DA neurons, may contribute to neuronal death by disrupting cell-cell and cell-ECM linkage (Kim et al. 2009).
A role of MMP-9 in the exacerbation of inflammation is also suggested by the results on parkinsonian macaques, where MPTP-induced long-lasting neuroinflammation correlates with progressive degeneration of nigro-striatal circuitry. The numbers of MMP- $9^{+}$striatal neurons and astrocytes increase when compared to control, suggesting that molecular signals released by "denervated" neurons and axons support the inflammatory environment. MMP-9 could be a good candidate, as can favor migration of glial cells by cleaving/modifying cell surface receptors, activating chemotactic factors and pro-inflammatory chemokines (IL-1 $\beta$, TNF- $\alpha$ ) (Kawasaki et al. 2008), and degrading ECM proteins. On the other hand, TNF- $\alpha$ and IL-1 $\beta$ induce a prominent release of MMP-9 by glial cells (Kauppinen and Swanson 2005), which in turn amplify their reactive state (Sbai et al. 2010), further modifying cell size and enhancing amoeboid movements (Fig. 12).

MMP activity can switch from harmful to reparative, allowing axon re-growth, remyelination and re-establishment of connectivity (Yong 2005; Agrawal et al. 2008, Huntley 2012; De Stefano et al. 2012). In particular, oligodendrocyte-derived MMP-9 supports oligodendrogliosis and myelin restoration (Uhm et al. 1998; Oh et al. 1999; Larsen et al. 2003). We previously demonstrated that MPTP treatment of both mice and monkeys induces a prominent oligodendrogliosis concomitant to the inflammatory process here described (Annese et al. 2013). In this study, a number of cells classified as "others", among which there are oligodendrocytes (unpublished observation), express MMP-9, both before and after MPTP treatment. Therefore, we hypothesize that, in parkinsonian mice, persistent expression of active MMP-9 may be implicated in late reparative processes by: mediating oligodendrogliosis, which implies myelin digestion and cell remodeling; favoring elongation and sprouting of regenerating axon once released by growth cones, by remodeling ECM proteins; supporting formation of new myelin sheaths and oligodendrocyte-axon connections (Larsen et al. 2003, 2006). These events have been summarized in the cartoon depicted in Fig. 12, which takes into account both previous (Annese et al. 2013) and present results for a more comprehensive picture.

Results obtained in MPTP-treated macaques differ, but do not contradict, those described in mice. Two years after establishment of stable Parkinsonism, in the monkey striatum both inflammation (this study; Barcia et al. 2004, 2011) and oligodendrogliosis (Annese et al. 2013) are significantly higher than in control animals. Differences inter species (macaque vs. mouse) and/or MPTP administration modality (chronic vs. acute) determine pathological traits more similar in the macaque to human PD. Therefore, neuronal damage initiates a cascade of glia-derived and auto-perpetuating 
Fig. 11 Glial cells activation (neuroinflammation) inversely correlates with the number of $\mathrm{TH}^{+}$cells in the substantia nigra $(\mathrm{SN})$ and levels of $\mathrm{TH}$ immunopositivity in the striatum. Increase in the mean cell area $\left(\mu \mathrm{m}^{2}\right)$ occupied by both microglia (Iba- $1^{+}$cells) and astrocytes $\left(\mathrm{GFAP}^{+}\right.$cells) inversely correlates to the levels of TH immunostaining in both $\mathrm{SN} p c$ and striatum of wild-type mice (black dots and black tendency lines). The inverse correlation is almost lost in the MMP-9 KO mice (red dots and red tendency lines). $n=15$ mice (wild-type) and 24 mice (MMP-9 KO). $p$ values, calculated by Pearson correlation coefficient $\left(R^{2}\right)$, are indicated for each graph

\section{Substantia nigra}

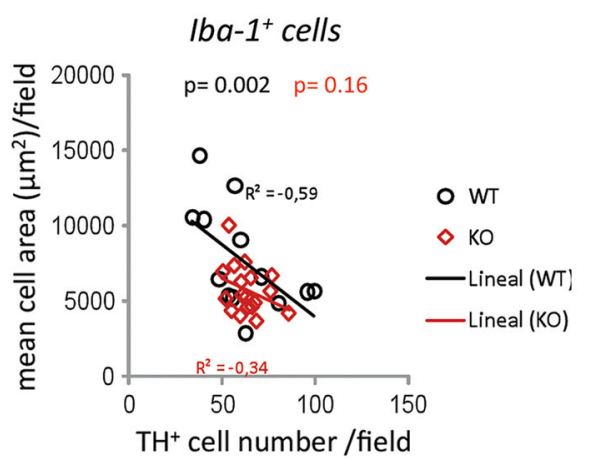

GFAP+ cells

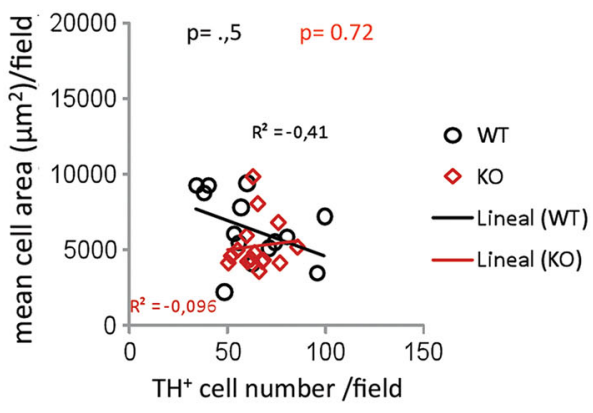

$\mathrm{Iba-1} 1^{+}$cells

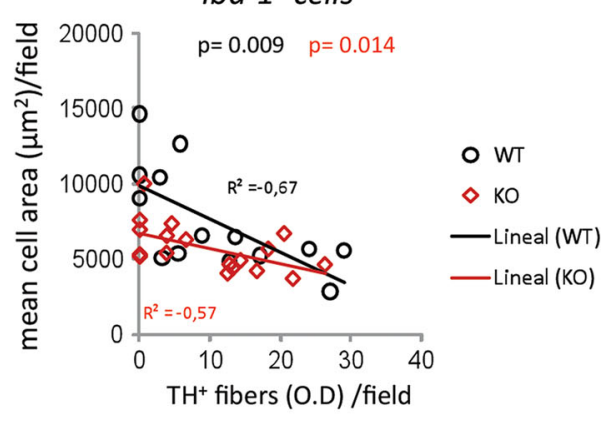

GFAP+ cells

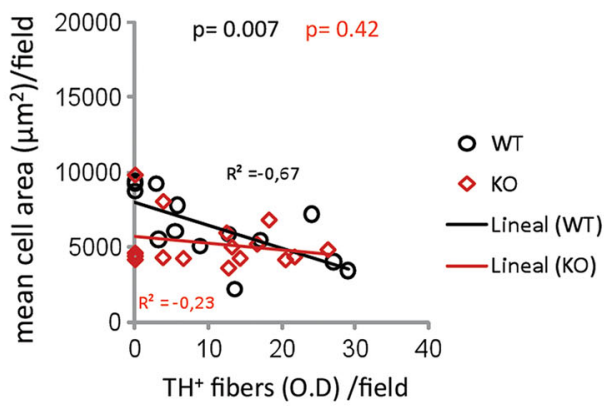

\section{Striatum}

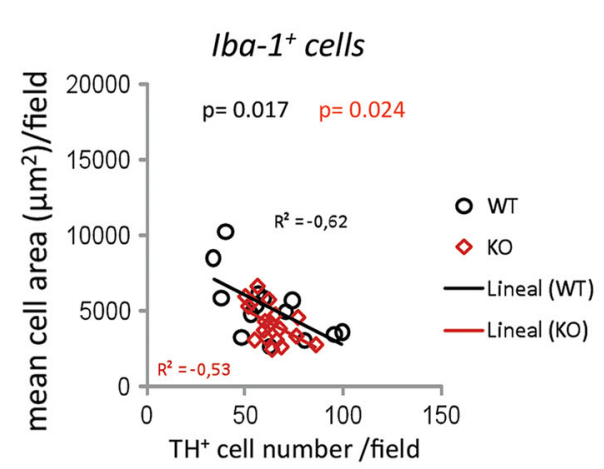

GFAP $P^{+}$cells

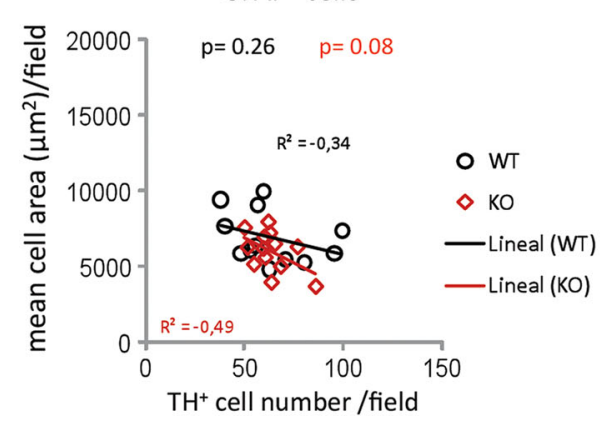

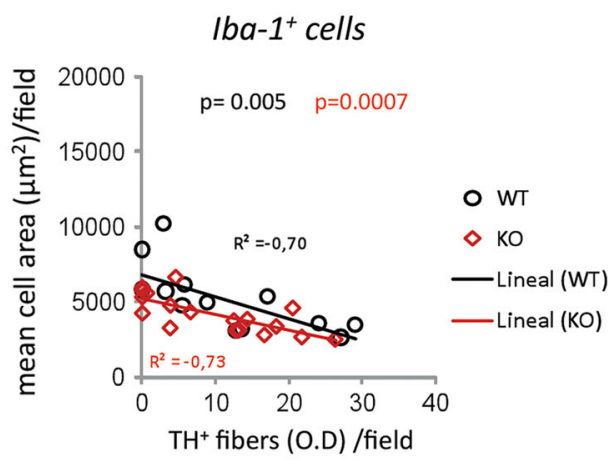

GFAP cells

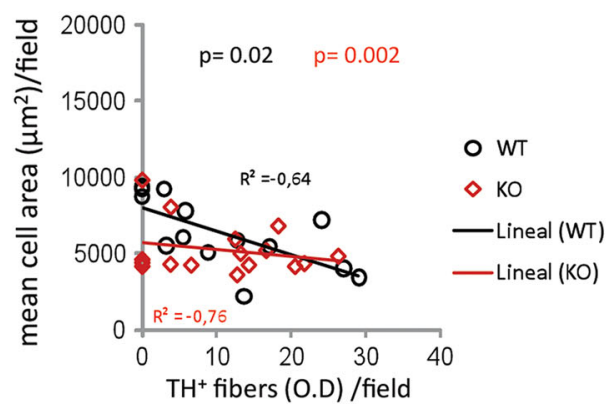

inflammatory signals, which favor progressive DA neuron loss (Brochard et al. 2009), and promote formation of a glial scar. This would impose a barrier to axon regeneration (Rolls et al. 2009) and create a hostile environment, in which oligodendrocyte activity becomes ineffective (Goldschmidt et al. 2009). 
Fig. 12 Synopsis of the response of the nigro-striatalcortical circuit to acute MPTP intoxication. In the dynamics of the events, the proposed role of MMP-9 in the exacerbation of dopaminergic neuron death and neuroinflammatory response is highlighted. Oligodendrocytes and the hypothesized role they may play in the process of partial recovery of the nigrostriatal pathway are also depicted

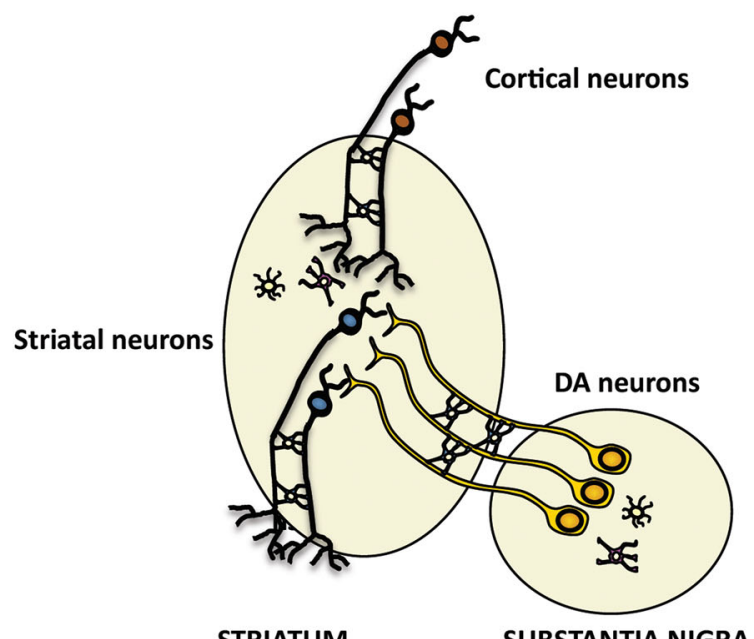

STRIATUM

SUBSTANTIA NIGRA

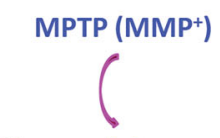

Neuronal damage (direct/indirect)

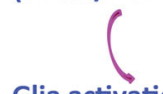

Glia activation and oligodendrogliosis

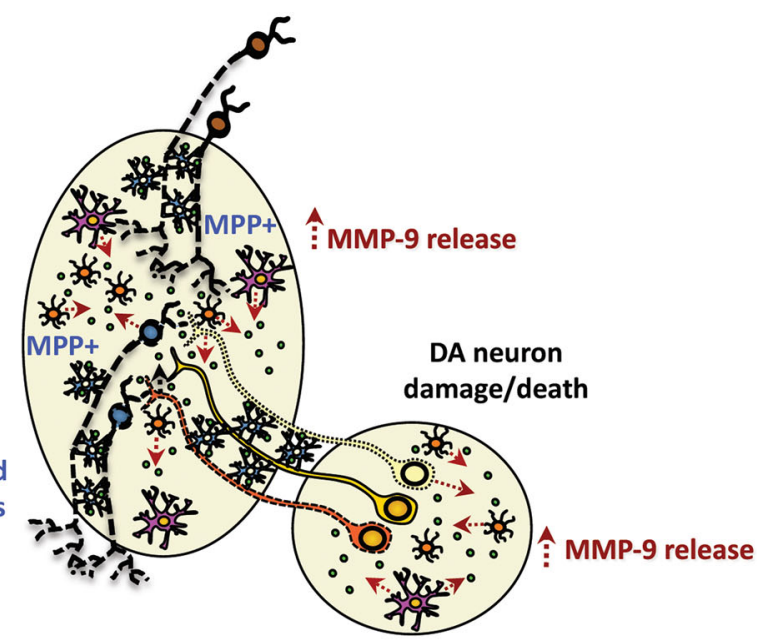

\begin{tabular}{|c|c|}
\hline 37 & microglia \\
\hline 读 & activated microglia \\
\hline د. & astrocyte \\
\hline Wy & reactive astrocyte \\
\hline$\$$ & oligodendrocyte \\
\hline 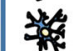 & reactive oligodendrocyte \\
\hline 。 & MMP-9 \\
\hline
\end{tabular}

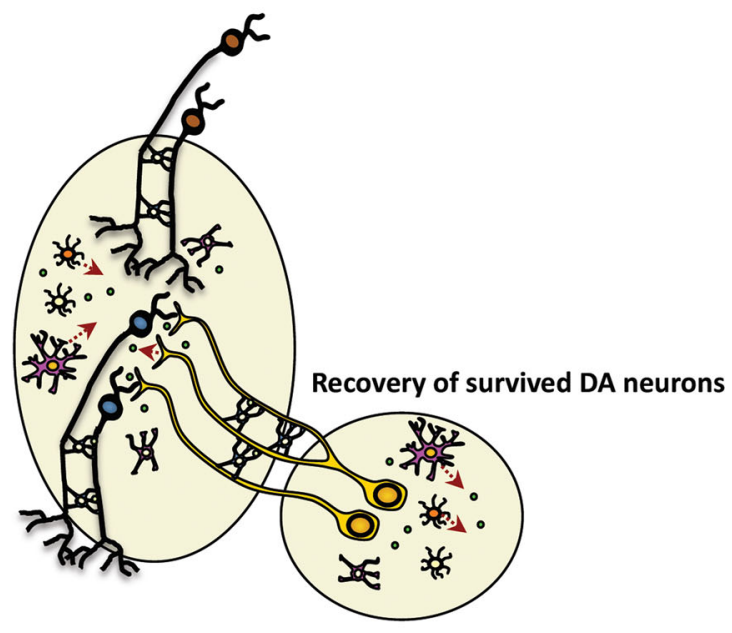

In conclusion, MMP-9 could be a possible therapeutic target for the treatment of acute neuroinflammation in Parkinsonism. However, MMP roles in physiological and reparative processes, and the perfect timing at which beneficial effects can revert into detrimental, complicate the efforts of treatment with MMP inhibitors. Therefore, models reproducing developmental stages of the disease are useful to clarify time and place of MMP activation to devise therapeutic strategies. 
Acknowledgments The authors wish to thank Prof. P. Paggi for her valuable comments and stimulating discussions. This work was supported by grants from: Ministero dell'Università e della Ricerca Scientifica (MIUR, Ricerche Universitarie 2011), Agenzia Spaziale Italiana (ASI) and Fundación Séneca (14902/IV10/10) to MEDS and by grants from: the Spanish Ministry of Science (SAF07-062262, FIS PI10-02827), Fundación Séneca (FS/15329/PI/10), UJI (13I004.01/1) and Centro de Investigación Biomédica en Red sobre Enfermedades Neurodegenerativas (CIBERNED) to MTH.

\section{References}

Agrawal SM, Lau L, Yong VW (2008) MMPs in the central nervous system: where the good guys go bad. Semin Cell Dev Biol 19:42-51

Annese V, Barcia C, Ros-Bernal F, Gómez A, Ros CM, De Pablos V, Fernández-Villalba E, De Stefano ME, Herrero MT (2013) Evidence of oligodendrogliosis in 1-methyl-4-phenyl-1,2,3,6tetrahydropyridine (MPTP)-induced Parkinsonism. Neuropathol Appl Neurobiol 39:132-143

Barcia C, Bautista V, Sánchez-Bahillo A, Fernández-Villalba E, Navarro-Ruis JM, Barreiro AF, Poza Y, Poza M, Herrero MT (2003) Circadian determinations of cortisol, prolactin and melatonin in chronic methyl-phenyl-tetrahydropyridine-treated monkeys. Neuroendocrinol 78:118-128

Barcia C, Sánchez-Bahillo A, Fernández-Villalba E, Bautista V, Poza Y, Poza M, Fernández-Barreiro A, Hirsch EC, Herrero MT (2004) Evidence of active microglia in substantia nigra pars compacta of parkinsonian monkeys 1 year after MPTP exposure. Glia 46:402-409

Barcia C, de Pablos V, Bautista-Hernández V, Sánchez-Bahillo A, Bernal I, Fernández-Villalba E, Martín J, Bañón R, FernándezBarreiro A, Herrero MT (2005) Increased plasma levels of TNFalpha but not of IL1-beta in MPTP-treated monkeys one year after the MPTP administration. Parkinsonism Relat Disord 11:435-439

Barcia C, Sanderson NSR, Barrett RJ, Wawrowsky K, Kroeger KM, Puntell M, Liu C, Castro MG, Lowenstein PR (2008) T cells' immunological synapses induce polarization of brain astrocytes in vivo and in vitro: a novel astrocyte response mechanism to cellular injury. PLoS One 3:e2977

Barcia C, Ros CM, Annese V, Gómez A, Ros-Bernal F, Aguado-Yera D, Martínez-Pagán ME, de Pablos V, Fernandez-Villalba E, Herrero MT (2011) IFN- $\gamma$ signaling, with the synergistic contribution of TNF- $\alpha$, mediates cell specific microglial and astroglial activation in experimental models of Parkinson's disease. Cell Death Dis 2:e142

Barnum CJ, Tansey MG (2010) Modeling neuroinflammatory pathogenesis of Parkinson's disease. Prog Brain Res 184:113-132

Bezard E, Dovero S, Imbert C, Boraud T, Gross CE (2000) Spontaneous long-term compensatory dopaminergic sprouting in MPTP-treated mice. Synapse 38:363-368

Braak H, Rüb U, Gai WP, Del Tredici K (2003) Idiopathic Parkinson's disease: possible routes by which vulnerable neuronal types may be subject to neuroinvasion by an unknown pathogen. J Neural Transm 110:517-536

Braak H, Del Tredici K, Rüb U, de Vos RA, Jansen Steur N, Braak E (2006) Staging of brain pathology related to sporadic Parkinson's disease. Neurobiol Aging 24:197-211

Braak H, Sastre M, Del Tredici K (2007) Development of $\alpha$-synuclein immunoreactive astrocytes in the forebrain parallels stages of intraneuronal pathology in sporadic Parkinson's disease. Acta Neuropathol 114:231-241
Brochard V, Combadière B, Prigent A, Laouar Y, Perrin A, BerayBerthat V, Bonduelle O, Alvarez-Fischer D, Callebert J, Launay JM, Duyckaerts C, Flavell RA, Hirsch EC, Hunot S (2009) Infiltration of $\mathrm{CD}^{4+}$ lymphocytes into the brain contributes to neurodegeneration in a mouse model of Parkinson disease. J Clin Invest 119:182-192

Candelario-Jalil E, Yang Y, Rosenberg GA (2009) Diverse roles of matrix metalloproteinases and tissue inhibitors of metalloproteinases in neuroinflammation and cerebral ischemia. Neuroscience 158:983-994

Choi DH, Kim EM, Son HJ, Joh TH, Kim D, Beal MF, Hwang O (2008) A novel intracellular role of matrix metalloproteinase-3 during apoptosis of dopaminergic cells. J Neurochem 106:405-415

De Stefano ME, Annese V, Barcia C, Ros Bernal F, FernandezVillalba E, Herrero MT (2012) Neuroinflammation in Parkinson's disease: a role for matrix metalloproteinases? In: Gemma C (ed) Neuroinflammation: pathogenesis, mechanisms and management. Nova Science Publishers Inc, Happauge

Del Signore A, De Sanctis V, Di Mauro E, Negri R, Perrone-Capano C, Paggi P (2006) Gene expression pathways induced by axotomy and decentralization of rat superior cervical ganglion neurons. Eur J Neurosci 23:65-74

Gerard M, Debyser Z, Desender L, Kahle PJ, Baert J, Baekelandt V, Engelborghs Y (2006) The aggregation of alpha-synuclein is stimulated by FK506 binding proteins as shown by fluorescence correlation spectroscopy. FASEB J 20:524-526

Goldschmidt T, Antel J, König FB, Brück W, Kuhlmann T (2009) Remyelination capacity of the MS brain decreases with disease chronicity. Neurology 72:1914-1921

Herkenham M, Little MD, Bankiewicz K, Yang SC, Markey SP, Johannessen JN (1991) Selective retention of MPP+ within the monoaminergic systems of the primate brain following MPTP administration: an in vivo autoradiographic study. Neuroscience 40:133-158

Herrero MT, Hirsch EC, Javoy-Agid F, Obeso JA, Agid Y (1993) Differential vulnerability to 1-methyl-4-phenyl-1,2,3,6-tetrahydropyridine of dopaminergic and cholinergic neurons in the monkey mesopontine tegmentum. Brain Res 624:281-285

Hirsch EC, Hunot S (2009) Neuroinflammation in Parkinson's disease: a target for neuroprotection? Lancet Neurol 8:382-397

Hirsh EC, Hunot S, Damier P, Faucheux B (1998) Glial cells and inflammation in Parkinson's disease: a role in neurodegeneration? Ann Neurol 44:S115-S120

Houlden H, Singleton AB (2012) The genetics and neuropathology of Parkinson's disease. Acta Neuropathol 124:325-338

Hunot S, Boissiere F, Faucheux B, Brugg B, Mouatt-Prigent A, Agid Y (1996) Nitric oxide synthase and neuronal vulnerability in Parkinson's disease. Neuroscience 72:355-363

Huntley GW (2012) Synaptic circuit remodelling by matrix metalloproteinases in health and disease. Nat Rev Neurosci 13:743-757

Jackson-Lewis V, Jakowec M, Burke RE, Przedborski S (1995) Time course and morphology of dopaminergic neuronal death caused by the neurotoxin 1-methyl-4-phenyl-1,2,3,6-tetrahydropyridine. Neurodegeneration 4:257-269

Kauppinen TM, Swanson RA (2005) Poly(ADP-ribose) polymerase-1 promotes microglial activation, proliferation, and matrix metalloproteinase-9-mediated neuron death. J Immunol 174: 2288-2296

Kawasaki Y, Xu ZZ, Wang X, Park JY, Zhuang ZY, Tan PH, Gao YJ, Roy K, Corfas G, Lo EH, Ji RR (2008) Distinct roles of matrix metalloproteases in the early- and late-phase development of neuropathic pain. Nat Med 14:331-336

Kim YS, Choi DH, Block ML, Lorenzl S, Yang L, Kim YJ, Sugama S, Cho BP, Hwang O, Browne SE, Kim SY, Hong J-S, Beal MF, Joh TH (2007) A pivotal role of matrix metalloproteinase-3 
activity in dopaminergic neuronal degeneration via microglial activation. FASEB J 21:179-180

Kim GW, Kim HJ, Cho KJ, Kim HW, Cho YJ, Lee BI (2009) The role of MMP-9 in integrin-mediated hippocampal cell death after pilocarpine-induced status epilepticus. Neurobiol Dis 36: 169-180

Kim E-M, Shin E-J, Choi JH, Son HJ, Park I-S, Joh TH, Hwang O (2010) Matrix metalloproteinase-3 is increased and participates in neuronal apoptotic signaling downstream of caspase-12 during endoplasmic reticulum stress. J Biol Chem 285:16444-16452

Kim SK, Kang SW, Kim DH, Yun DH, Chung JH, Ban JY (2011) Matrix metalloproteinase-3 gene polymorphisms are associated with ischemic stroke. J Interferon Cytokine Res 32:81-86

Langston JW, Ballard P, Tetrud JW, Irwin I (1983) Chronic Parkinsonism in humans due to a product of meperidine-analog synthesis. Science 219:979-980

Larsen PH, Wells JE, Stallcup WB, Opdenakker G, Yong VW (2003) Matrix metalloproteinase- 9 facilitates remyelination in part by processing the inhibitory NG2 proteoglycan. J Neurosci 23:11127-11135

Larsen PH, DaSilva AG, Conant K, Yong VW (2006) Myelin formation during development of the CNS is delayed in matrix metalloproteinase-9 and -12 null mice. J Neurosci 26:2207-2214

Leonardo CC, Pennypacker KR (2009) Neuroinflammation and MMPs: potential therapeutic targets in neonatal hypoxic-ischemic injury. J Neuroinflammation 6:13

L'Episcopo F, Tirolo C, Caniglia S, Testa N, Serra PA, Impagnatiello F, Morale MC, Marchetti B (2010) Combining nitric oxide release with anti-inflammatory activity preserves nigrostriatal dopaminergic innervation and prevents motor impairment in a 1-methyl-4-phenyl-1,2,3,6-tetrahydropyridine model of Parkinson's disease. J Neuroinflammation 7:83

Livak KJ, Schmittgen TD (2001) Analysis of relative gene expression data using real-time quantitative PCR and the 2(-Delta Delta $\mathrm{C}(\mathrm{T})$ ). Methods 25:402-408

Lorenzl S, Albers DS, Narr S, Chirichigno J, Beal MF (2002) Expression of MMP-2, MMP-9, and MMP-1 and their endogenous counterregulators TIMP-1 and TIMP-2 in postmortem brain tissue of Parkinson's disease. Exp Neurol 178:13-20

Lorenzl S, Calingasan N, Yang L, Albers DS, Shugama S, Gregorio J, Krell HW, Chirichigno J, Joh T, Beal MF (2004) Matrix metalloproteinase-9 is elevated in 1-methyl-4-phenyl-1,2,3,6tetrahydropyridine-induced parkinsonism in mice. Neuromol Med 5:119-132

McGeer PL, Itagaki S, Boyes BE, McGeer EG (1988) Reactive microglia are positive for HLA-DR in the substantia nigra of Parkinson's and Alzheimer's disease brains. Neurology 38:1285-1291

Mounayar S, Boulet S, Tandé D, Jan C, Pessiglione M, Hirsch EC, Féger J, Savasta M, François C, Tremblay L (2007) A new model to study compensatory mechanisms in MPTP-treated monkeys exhibiting recovery. Brain 130:2898-2914

Nagatsu T, Mogi M, Ichinose H, Togari A (2000) Changes in cytokines and neurotrophins in Parkinson's disease. Neural Transm Suppl 60:277-290

Oh LY, Larsen PH, Krekoski CA, Edwards DR, Donovan F, Werb Z, Yong VW (1999) Matrix metalloproteinase-9/gelatinase B is required for process outgrowth by oligodendrocytes. J Neurosci 19:8464-8475

Ouchi Y, Yoshikawa E, Sekine Y, Futatsubashi M, Kanno T, Ogusu $\mathrm{T}$, Torizuka $\mathrm{T}$ (2005) Microglial activation and dopamine terminal loss in early Parkinson's disease. Ann Neurol 57:168-175

Ouchi Y, Yagi S, Yokokura M, Sakamoto M (2009) Neuroinflammation in the living brain of Parkinson's disease. Parkinsonism Relat Disord Suppl 3:S200-S204

Page-McCaw A, Ewald AJ, Werb Z (2007) Matrix metalloproteinases and the regulation of tissue remodelling. Nat Rev Mol Cell Biol 8:221-233

Parks WC, Wilson CL, Lopez-Boado YS (2004) Matrix metalloproteinases as modulators of inflammation and innate immunity. Nat Rev Immunol 4:617-629

Pott Godoy MC, Tarelli R, Ferrari CC, Sarchi MI, Pitossi FJ (2008) Central and systemic IL-1 exacerbates neurodegeneration and motor symptoms in a model of Parkinson's disease. Brain 131:1880-1894

Rolls A, Shechter R, Schwartz M (2009) The bright side of the glial scar in CNS repair. Nat Rev Neurosci 10:235-241

Sbai O, Ould-Yahoui A, Ferhat L, Gueye Y, Bernard A, Charrat E, Mehanna A, Risso JJ, Chauvin JP, Fenouillet E, Rivera S, Khrestchatisky M (2010) Differential vesicular distribution and trafficking of MMP-2, MMP-9, and their inhibitors in astrocytes. Glia 58:344-366

Streit WJ, Kreutzberg GW (1987) Lectin binding by resting and reactive microglia. J Neurocytol 16:249-260

Streit WJ, Walter SA, Pennell NA (1999) Reactive microgliosis. Progr Neurobiol 57:563-581

Tansey MG, Goldberg MS (2010) Neuroinflammation in Parkinson's disease: its role in neuronal death and implication for therapeutic intervention. Neurobiol Dis 37:510-518

Uhm JH, Dooley NP, Oh LY, Yong VW (1998) Oligodendrocytes utilize a matrix metalloproteinase, MMP-9, to extend processes along an astrocyte extracellular matrix. Glia 22:53-63

Walker EJ, Rosenberg GA (2010) Divergent role for MMP-2 in myelin breakdown and oligodendrocyte death following transient global ischemia. J Neurosci Res 88:764-773

Walsh S, Finn DP, Dowd E (2011) Time-course of nigrostriatal neurodegeneration and neuroinflammation in the 6-hydroxydopamine-induced axonal and terminal lesion models of Parkinson's disease in the rat. Neuroscience 175:251-261

Whitton PS (2010) Neuroinflammation and the prospects for antiinflammatory treatment of Parkinson's disease. Curr Opin Investig Drugs 11:788-794

Wilczynski GM, Konopacki FA, Wilczek E, Lasiecka Z, Gorlewicz A, Michaluk P, Wawrzyniak M, Malinowska M, Okulski P, Kolodziej LR, Konopka W, Duniec K, Mioduszewska B, Nikolaev E, Walczak A, Owczarek D, Gorecki DC, Zuschratter W, Ottersen OP, Kaczmarek L (2008) Important role of matrix metalloproteinase 9 in epileptogenesis. J Cell Biol 180: 1021-1035

Woo MS, Park JS, Choi IY, Kim WK, Kim HS (2008) Inhibition of MMP-3 or -9 suppresses lipopolysaccharide-induced expression of proinflammatory cytokines and iNOS in microglia. J Neurochem 106:770-780

Wright JW, Harding JW (2009) Contributions of matrix metalloproteinases to neural plasticity, habituation, associative learning and drug addiction. Neural Plast 2009:579382

Yong VW (2005) Metalloproteinases: mediators of pathology and regeneration in the CNS. Nat Rev Neurosci 6:931-944

Zhang H, Adwanikar H, Werb Z, Noble-Haeusslein LJ (2010) Matrix metalloproteinases and neurotrauma: evolving roles in injury and reparative processes. Neuroscientist 16:156-170 